\title{
Article
}

\section{Dual UV-Thermal Curing of Biobased Resorcinol Epoxy Resin-Diatomite Composites with Improved Acoustic Performance and Attractive Flame Retardancy Behavior}

\author{
Quoc-Bao Nguyen ${ }^{1,2,3}$, Henri Vahabi ${ }^{4}{ }^{\circledR}$, Agustín Rios de Anda ${ }^{1}$, Davy-Louis Versace ${ }^{1}$, Valérie Langlois ${ }^{1}$, \\ Camille Perrot ${ }^{2,3}$, Vu-Hieu Nguyen ${ }^{2,3}$, Salah Naili ${ }^{2,3}$ and Estelle Renard ${ }^{1, *}$ \\ 1 Paris-Est Institute of Chemistry and Materials (ICMPE), University Paris Est Creteil, F-94320 Thiais, France; \\ quoc-bao.nguyen@u-pec.fr (Q.-B.N.); rios@icmpe.cnrs.fr (A.R.d.A.); versace@icmpe.cnrs.fr (D.-L.V.); \\ langlois@icmpe.cnrs.fr (V.L.) \\ 2 Multi-Scale Modeling and Simulation Laboratory (MSME), University Gustave Eiffel, \\ F-77454 Marne-la-Vallée, France; camille.perrot@univ-eiffel.fr (C.P.); \\ vu-hieu.nguyen@univ-paris12.fr (V.-H.N.); naili@u-pec.fr (S.N.) \\ 3 Multi-Scale Modeling and Simulation Laboratory (MSME), University Paris Est Creteil, \\ F-94010 Creteil, France \\ 4 Optical Materials, Photonics and Systems Laboratory (LMOPS), Université de Lorraine, F-57000 Metz, France; \\ henri.vahabi@univ-lorraine.fr \\ * Correspondence: renard@icmpe.cnrs.fr
}

Citation: Nguyen, Q.-B.; Vahabi, H.; Rios de Anda, A.; Versace, D.-L.; Langlois, V.; Perrot, C.; Nguyen, V.-H.; Naili, S.; Renard, E. Dual UV-Thermal Curing of Biobased Resorcinol Epoxy Resin-Diatomite Composites with Improved Acoustic Performance and Attractive Flame Retardancy Behavior. Sustain. Chem. 2021, 2, 24-48. https://doi.org/10.3390/ suschem 2010003

Received: 2 November 2020 Accepted: 29 December 2020 Published: 14 January 2021

Publisher's Note: MDPI stays neutral with regard to jurisdictional clai$\mathrm{ms}$ in published maps and institutional affiliations.

Copyright: (c) 2021 by the authors. Licensee MDPI, Basel, Switzerland. This article is an open access article distributed under the terms and conditions of the Creative Commons Attribution (CC BY) license (https:// creativecommons.org/licenses/by/ $4.0 /)$

\begin{abstract}
This study has developed novel fully bio-based resorcinol epoxy resin-diatomite composites by a green two-stage process based on the living character of the cationic polymerization. This process comprises the photoinitiation and subsequently the thermal dark curing, enabling the obtaining of thick and non-transparent epoxy-diatomite composites without any solvent and aminebased hardeners. The effects of the diatomite content and the compacting pressure on microstructural, thermal, mechanical, acoustic properties, as well as the flame behavior of such composites have been thoroughly investigated. Towards the development of sound absorbing and flame-retardant construction materials, a compromise among mechanical, acoustic and flame-retardant properties was considered. Consequently, the composite obtained with $50 \mathrm{wt}$ \% diatomite and $3.9 \mathrm{MPa}$ compacting pressure is considered the optimal composite in the present work. Such composite exhibits the enhanced flexural modulus of $2.9 \mathrm{MPa}$, a satisfying sound absorption performance at low frequencies with Modified Sound Absorption Average (MSAA) of 0.08 (for a sample thickness of only $5 \mathrm{~mm}$ ), and an outstanding flame retardancy behavior with the peak of heat release rate (pHRR) of $109 \mathrm{~W} / \mathrm{g}$ and the total heat release of $5 \mathrm{~kJ} / \mathrm{g}$ in the pyrolysis combustion flow calorimeter (PCFC) analysis.
\end{abstract}

Keywords: resorcinol epoxy resin; diatomite; composite; cationic polymerization; photochemistry; mechanical properties; sound absorption; flame retardancy

\section{Introduction}

Diatomite is composed of sediments enriched with silica in the form of siliceous skeletons of diatoms which are a collection of diverse microscopic single-celled algae. The varied and complex structures of these siliceous skeletons bestow unique properties upon diatomite. Indeed, it is widely used due to its high porosity (up to 90\%), excellent liquid absorption capacity, low density, non-toxicity, great abundance, and low cost [1-3]. Adapted for different applications, diatomite exists in various forms including $0.5-3 \mathrm{~mm}$ granules for absorbents, powder for natural mineral fillers, or dust for production of insulation materials. It is used to form light and porous ceramics for construction thanks to its thermal insulation properties and capacity for humidity control [4-6]. The production of these ceramics is carried out by sintering, which normally requires high operating temperatures. Although mixing diatomite with agricultural residues such as ash from Brazil nut 
shells [7] or with tourmaline as well as sintering additives [8] helps to reduce the sintering temperature, this process remains considerably energy-consuming. The development of composites using diatomite as siliceous fillers is an alternative to the sintering technique for advanced diatomite-based material prospects. Examples of composites using diatomite in various types of polymeric matrices such as epoxy [9], polyacrylate [10], polyetherimide [11], polyurethane [12], polylactide [13], chitosan [14], or different kinds of rubber [15] have shown the improvement of thermal stability and mechanical properties of composites. In these researches, the fillers have been incorporated at a rate not exceeding $15 \%$ by weight for the mechanical reinforcement purpose. Additionally, diatomite can be also combined with, for instance paraffin [16] or sodium nitrate [17], to make composite phase change materials for thermal energy storage applications. Considering the increase in demand for sound absorbing porous composites in construction, it seems interesting to study the potential of diatomite granules as porous fillers for the preparation of porous epoxy composites. Indeed, epoxy resins are materials of growing interest in many areas because of their superior chemical resistance, excellent mechanical and thermal properties as well as relatively low price $[18,19]$. These properties are due to their cross-linked structure and the presence of aromatic rings in the monomers such as diglycidyl ether bisphenol A (DGEBA) for some technical resins [20]. However, the production and applications of these resins have been faced with environmental challenges and human health issues as regards their dependence on fossil resources and harmfulness of bisphenol A [21-23]. For sustainable development, it is crucial to develop more environmentally friendly materials, and therefore to find alternatives to the use of DGEBA. In a previous work, the preparation of a bio-sourced epoxy resin from resorcinol diglycidyl ether (RDGE) has been performed using cationic photopolymerization under UV light exposure in our laboratory [24]. This process follows the principles of green chemistry due to numerous advantages such as simple equipment, unpolluted formulations, reduced cycle time and particularly absence of solvents as well as harmful amine-based hardeners [25]. The use of such formulations to prepare fully bio-sourced epoxy-diatomite composites seems particularly attractive for developing new functional materials fulfilling environmental criteria.

The use of porous diatomite granules could generate porosity for the composites, thus enhancing their sound absorption performance [26]. Despite this fact, to the best of our knowledge, only a very scarce number of works have studied this aspect, leaving the influence of diatomite on the acoustic behavior of the diatomite-based composites as a subject to be explored. The incorporation of siliceous diatomite is also expected to decrease the high inflammability of epoxy resins. Indeed, silicon compounds could be utilized individually $[27,28]$ or in conjunction with other flame retardants such as phosphorus-based ones [29-31] to provide attractive thermal resistance and flame retardancy performances of epoxy-based composites. Despite these advantages, the elaboration of such kind of composites based on photopolymerization is hindered by limitations in the radiation process. Indeed, the opaque nature of diatomite prevents the infiltration of $\mathrm{UV}$ radiations into the formulation; hence, precluding the cross-linking of the resin. A similar phenomenon can be also observed in a bulk polymerization situation in which the resin portion closest to the source of radiation is generally cross-linked first, forming a non-transparent resin layer stopping the penetration of radiations and thus leaving the rest of the formulation non cross-linked [24].

The objective of this paper is to develop thick and non-transparent composites by photochemistry from the commercially available resorcinol derivative called resorcinol diglycidyl ether (RDGE) as a monomer and granular diatomite as fillers. In order to overcome the above-mentioned drawbacks concerning the radiation process, an alternative photochemical approach to the process established in our previous work on the bulk resorcinol epoxy resin [24] has been developed, based on characteristics of the cationic polymerization of epoxies. On the one hand, this kind of polymerization exhibits a slow polymerization rate, particularly in case of monomers of the phenyl glycidyl ether type with the presence of a slow induction phase [32]. On the other hand, active centers generated 
during the cationic polymerization have an extremely long lifetime. These two features give this type of polymerization a "living" character [33], enabling the development of a two-stage process. Thus, the polymerization can be initiated under radiation, and then continued by thermal activation without any light source. The composite systems resulting from this practical process are amine- and solvent-free. During the elaboration of such composites, the compaction step in which a pressure was applied to the composite formulation for attaining homogeneous distribution of the resin matrix around diatomite fillers was also conducted. The influences of the compacting pressure and the diatomite content on the microstructural, mechanical, acoustic absorption and flame-retardant properties of epoxy-diatomite composites were thoroughly investigated.

\section{Experimental}

\section{Materials}

Resorcinol diglycidyl ether (RDGE) was obtained from Sigma Aldrich. DeuteronUV1242 (bis (dodecylphenyl) iodonium hexafluoro-antimonate), hereafter called Iod, was supplied by Deuteron $\mathrm{GmbH}$. Granular calcinated diatomite with size ranging from 0.3 to $0.7 \mathrm{~mm}$ and apparent density of $0.53 \mathrm{~g} / \mathrm{cm}^{3}$ was purchased from Denios. The calcination treatment of raw diatomite removes pore-clogging impurities. All these chemicals were used as received without any further purification procedure.

\section{Sample preparation}

Mixtures composed of RDGE as a monomer and Iod as a photoinitiator were pretreated in a convection oven at $90{ }^{\circ} \mathrm{C}$ for $10 \mathrm{~min}$ and then stirred thoroughly to liquefy and homogenize the reactants. The liquid mixtures were then stirred using a magnetic bar at $7 \mathrm{rpm}$ and irradiated by a UV lamp at room temperature under air simultaneously. The irradiation unit was a Hg-Xe Hamamatsu lamp with a broad emission spectral range from 250 to $450 \mathrm{~nm}$ (Lightning Cure LC8 (L8251), $200 \mathrm{~W}$ ) coupled to a flexible light guide. The irradiation intensity of this polychromatic lamp was $22 \mathrm{~mW} / \mathrm{cm}^{2}$ at $20.5 \mathrm{~cm}$ from the irradiation source. The irradiation step was conducted in a manner so that the mixtures remained liquid after irradiated.

To prepare porous composites with diatomite inclusions, the photoinitiated mixtures (RDGE + Iod) were poured down the molds and left at room temperature for $10 \mathrm{~min}$ to increase their viscosity, restricting their penetration later in diatomite grains. The diatomite grains were then poured over the molds and stirred carefully with the resin mixtures until complete impregnation by the resin was observed; i.e., diatomite's color turned somber when in contact with the resin mixtures. Afterwards, the resin-diatomite mixtures were put under compression loading for $1 \mathrm{~min}$ by a Specac manual hydraulic press providing a maximum load configuration of 15 tons. Compacted mixtures were then separated from the molds and placed in the convection oven for thermal treatment. The weight ratio of the photoinitiator with respect to the monomer and of the diatomite with respect to the total formulation, the irradiation time, the thermal treatment conditions, and the compaction pressure were investigated in this work.

Two types of molds were utilized: rectangular prism molds with inner cross-sectional dimensions of $40 \times 10 \mathrm{~mm}^{2}$ to fabricate samples for three-point bending tests and cylindrical molds with inner diameter of $40 \mathrm{~mm}$ to produce samples for acoustic tests. The height of both types of molds allows to obtain samples with the maximum thickness of $35 \mathrm{~mm}$. The absolute quantities of substances which were taken to make composite samples depend on the weight ratios of substances, the expected sample dimensions and the compaction pressure as well. For instance, regarding the optimal composite obtained in this study, rectangular-prism-shaped samples with the thickness of $3 \mathrm{~mm}$ and compaction pressure of 3.9 MPa were made by taking $1159.4 \mathrm{mg}$ RDGE, $40.6 \mathrm{mg}$ Iod, and $1200 \mathrm{mg}$ diatomite, whereas cylindrical samples with the thickness of $5 \mathrm{~mm}$ and compaction pressure of 3.9 MPa were fabricated with $4830.9 \mathrm{mg}$ RDGE, $169.1 \mathrm{mg}$ Iod, and $5000 \mathrm{mg}$ diatomite. 
Note that these two kinds of samples resulted from the same elaboration process and hence represented the same material.

\section{Experimental Techniques}

Fourier transform infrared (FTIR) spectra were recorded on a Bruker Tensor $27 \mathrm{spec}-$ trometer equipped with an ATR apparatus with a wavenumber range of $4000-400 \mathrm{~cm}^{-1}$. The epoxy conversion was calculated by means of infrared spectroscopy from the $908 \mathrm{~cm}^{-1}$ band assigned to epoxy bonds and the bands corresponding to aromatic $\mathrm{C}=\mathrm{C}$ bonds at $1400-1530 \mathrm{~cm}^{-1}$. The relative conversion $\alpha$ was calculated according to the following equation:

$$
\alpha=\left(\frac{R_{0}-R_{t}}{R_{0}}\right) \times 100
$$

with the ratio before irradiation $R_{0}=A_{\text {epoxy }} / A_{C=C \text {, ar }}$, where $A_{\text {epoxy }}$ corresponds to the area of the band at $908 \mathrm{~cm}^{-1}$ and $A_{C=C, a r}$ is the area of the bands between 1400 and $1530 \mathrm{~cm}^{-1}$.

The true density of diatomite was determined by a Quantachrome Ultrapyc 1200e helium pycnometer. The X-ray diffraction (XRD) analysis of diatomite was undertaken using a D8-Bruker diffractometer equipped with a Lynxeye rapid detector with the following processing parameters: the voltage of $40 \mathrm{kV}$, a current of $40 \mathrm{~mA}$, a power of $1600 \mathrm{~W}$, and an angle sweep $2 \theta$ from $5^{\circ}$ to $80^{\circ}$ with a step of $0.01^{\circ}$.

Mercury intrusion porosimetry (MIP) analyses were conducted on diatomite by a Micromeritics AutoPore IV 9500 porosimeter yielding a maximum pressure of 33,000 psia (about $227.5 \mathrm{MPa}$ ) and measures the pore diameter of the range from 0.003 to $360 \mu \mathrm{m}$. During MIP analyses, mercury is intruded at low pressures to fill in large pores and then at high pressures to fill in small pores. The intruded mercury volume is recorded at each pressure level, establishing the relation between these two parameters. This relation is then converted into the relation between the intruded mercury volume and the pore size by using Washburn's equation which, with the assumption that the pore geometry is cylindrical, relates pressures needed to force mercury into pores and the corresponding pore sizes as follows [34]:

$$
P=2 \gamma \cos \theta / r
$$

where $P$ is the applied pressure, $r$ is the corresponding pore radius, $\gamma$ is the surface tension of mercury and $\theta$ is the contact angle between the solid and mercury. From the volume of the penetrometer and the intruded mercury volume recorded at each pressure, the volume of open pore $V_{p}$ which is the total volume of intruded mercury and the bulk volume of the sample $V_{b}$ which includes the pore volume and the matrix volume can be identified [35], leading to the determination of the material porosity $\phi$ by the following equation:

$$
\phi=V_{p} / V_{b}
$$

Scanning electron microscopy (SEM) analyses were carried out on a Merlin microscope (Carl Zeiss Company, Jena, Germany) using SE2, BSE and InLens detectors with a $30 \mu \mathrm{m}$ diaphragm aperture and an accelerating tension of 2 to $3 \mathrm{kV}$. The acquisition of SEM micrographs was achieved by the combination of the energy dispersive $\mathrm{X}$-ray (EDX) and electron backscatter diffraction (EBSD) (Oxford Instruments Company, Oxford, UK) microanalysis systems. Before analyses, samples were coated with a 4-nm layer of palladium/platinum alloy in a Cressington 208 HR sputter-coater. The pore number distribution was determined through the post-processing of SEM images by means of the software ImageJ.

Differential scanning calorimetry (DSC) analyses were carried out on a TA Instruments Q25 DSC. As water traces were found in the samples, the Modulated mode was utilized to perform the analyses for characterizing the glass transition temperature $\left(T_{g}\right)$ of the materials while avoiding any signal pollution caused by the water evaporation during the analyses. Samples of about $15 \mathrm{mg}$ were heated from $25^{\circ} \mathrm{C}$ to either $200^{\circ} \mathrm{C}$ or $250^{\circ} \mathrm{C}$ at a rate of $3{ }^{\circ} \mathrm{C} / \mathrm{min}$, with temperature modulation of $\pm 2{ }^{\circ} \mathrm{C}$ and a period of $60 \mathrm{~s}$ under a nitrogen 
flow of $50 \mathrm{~mL} / \mathrm{min}$. Analyzing the reversing heat flow signal allowed to determine $T_{g}$ of which the value was taken at the half height of the step-change in the signal [36-38].

Thermogravimetric analyses (TGA) were conducted on a Setaram Setsys Evolution 16 apparatus. Samples were heated from $20^{\circ} \mathrm{C}$ to $30^{\circ} \mathrm{C}$ at $10^{\circ} \mathrm{C} / \mathrm{min}$ and kept at $30^{\circ} \mathrm{C}$ for $10 \mathrm{~min}$ for stabilization, then heated from $30^{\circ} \mathrm{C}$ to $800^{\circ} \mathrm{C}$ at $10{ }^{\circ} \mathrm{C} / \mathrm{min}$ under the air atmosphere. Finally, they were cooled from $800{ }^{\circ} \mathrm{C}$ to $30^{\circ} \mathrm{C}$ at $30{ }^{\circ} \mathrm{C} / \mathrm{min}$ and kept at $30^{\circ} \mathrm{C}$ for $30 \mathrm{~min}$. Two samples per formulation were tested.

Flexural properties were characterized by three-point bending tests using an Instron 5965 Universal Testing Machine equipped with a $100 \mathrm{~N}$ force cell. Samples of $40 \times 10 \times$ $(3 \pm 0.5) \mathrm{mm}^{3}$ were tested with a crosshead speed of $5 \mathrm{~mm} / \mathrm{min}$. The distance between supports was of $80 \%$ of the total length according to the ASTM D790 standard [39] (i.e., $32 \mathrm{~mm}$ ). The displacement was taken from the crosshead displacement. Five samples per formulation were characterized.

The materials' sound absorption coefficients were identified by three-microphone impedance tube experiments of which the configuration is shown in Figure 1. The impedance tube has a length of $1 \mathrm{~m}$ and an inner diameter of $40 \mathrm{~mm}$. The distances between microphones are Mic. 1-Mic. 2: $35 \mathrm{~mm}$, Mic. 1-Mic. 3: $115 \mathrm{~mm}$. Experiments were conducted in case of the normal incidence sound along with the rigid impervious backing. The absorption performance was characterized within the frequency range from 4 to $4500 \mathrm{~Hz}$ with a step of $4 \mathrm{~Hz}$. Each microphone measures the acoustic pressures at its respective position and the data are transferred to the computer equipped with the TubeCell software developed by Matelys Research Lab. This software processes the pressure data and computes acoustic properties according to the standard ISO 10534-2 [40] and the work of Salissou et al. [41]. Two cylindrical samples with a diameter of $40 \mathrm{~mm}$ and a thickness of $5 \mathrm{~mm}$ were tested for each formulation. For each sample, two experiments were carried out alternately for two opposite incidence surfaces. To avoid sound leakage as well as the sample displacement, Teflon ribbons were wrapped around the sample circumference. The experimental results of sound absorption coefficients are presented in terms of mean values at each frequency.

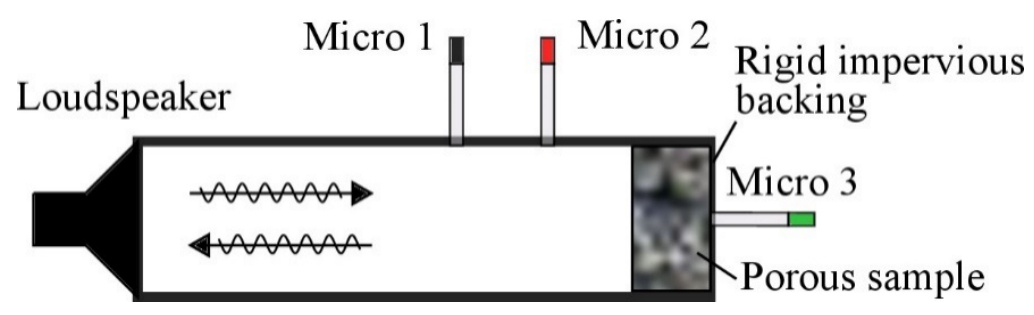

Figure 1. Configuration of three-microphone impedance tube experiments.

In order to conveniently assess the sound absorption performance of the studied materials at low frequencies, a single-number rating called modified sound absorption average (MSAA) is used in this paper. This single-number rating is based on the sound absorption average (SAA) which is suggested in the standard ASTM C423 [42]. The difference between these two single-number ratings is that while the SAA is the average, rounded off to the nearest 0.01 , of the sound absorption coefficients of a material for the twelve one-third octave bands from 200 to $2500 \mathrm{~Hz}$, namely, 200, 250, 315, 400, 500, 630, 800, 1000, 1250, 1600,2000 , and $2500 \mathrm{~Hz}$, the MSAA is the average, rounded off to the nearest 0.01 , of the sound absorption coefficients for only the seven one-third octave bands from 630 to 2500 $\mathrm{Hz}$ according to the following equation:

$$
\text { MSAA }=\frac{1}{7} \sum_{f_{i}=630}^{2500} \alpha_{a}\left(f_{i}\right)
$$

where $\alpha_{a}\left(f_{i}\right)$ is the sound absorption coefficient at frequency $f_{i}$. This modification aims to avoid the range of very low frequencies in which the measurements of the sound 
absorption coefficient often encounter noticeable fluctuations as well as unphysical values. Following the definition of the SAA, the MSAA also varies from 0 to 1 : MSAA $=0$ implies a perfect sound reflection and MSAA $=1$ signifies a perfect sound absorption.

The flammability behavior was investigated using pyrolysis combustion flow calorimeter analysis (PCFC), from Fire Testing Technology Company, West Sussex, UK. At a heating rate of $1{ }^{\circ} \mathrm{C} / \mathrm{s}$, small amounts of samples $(2-4 \mathrm{mg})$ were pyrolyzed under nitrogen up to $750{ }^{\circ} \mathrm{C}$. Gases produced from sample pyrolysis were collected and sent into a chamber containing oxygen $(20 \%)$ at $900{ }^{\circ} \mathrm{C}$. The quantity of consumed oxygen was measured and flammability parameters were obtained, based on Huggett's relation [43]: $1 \mathrm{~kg}$ of consumed oxygen corresponds to $13.1 \mathrm{MJ}$ of released energy. Values of peak of heat release rate ( $\mathrm{pHRR})$, temperature at $\mathrm{pHRR}\left(T_{\mathrm{pHRR}}\right)$ and total heat release (THR), were then determined. Vertical burning tests were also performed and dimensions of specimens were $40 \times 10$ $\times(3 \pm 0.5) \mathrm{mm}^{3}$. Samples were positioned vertically and a Bunsen burner flame was applied for $3 \mathrm{~s}$ or $9 \mathrm{~s}$. A descriptive scheme of this kind of flame test is presented in Figure 2. Moreover, tests' digital videos were recorded and selected images were also extracted. All videos are available in Supplementary Material.

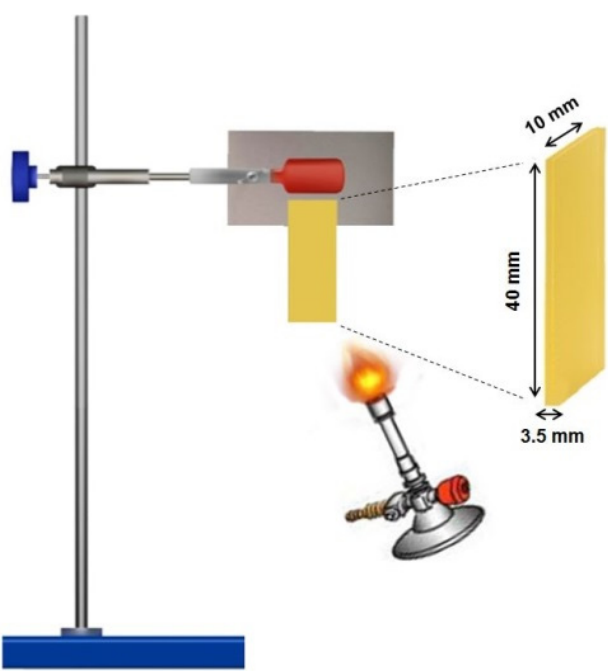

Figure 2. Scheme of the vertical flame set-up used in this work.

\section{Results and Discussion}

\subsection{Photoinitiation and Thermal Dark Curing Process}

In the first stage, we developed the polymerization of a transparent resin consisting only of the resorcinol monomer (RDGE) and the photoinitiator (Iod) by separating the process in two dissociated steps: initiation under UV light and polymerization under thermal activation sheltered from any light irradiation. The resin was irradiated for a very short time under magnetic agitation in order to homogeneously create active centers of oxonium-ion type which will be able to propagate during the thermal post-polymerization step. A preliminary study made it possible to fix the duration of irradiation inducing the photolysis of the initiator without leading to a gelification phenomenon. It is essential that the resin remains liquid or even viscous so that in the second stage it can be mixed with a filler to make the various composites. For a constant amount of Iod (1 wt.\% with respect to the monomer weight), the UV irradiation time varied from 2 to $10 \mathrm{~min}$ followed by a thermal treatment for $24 \mathrm{~h}$ at $90^{\circ} \mathrm{C}$. The duration of photoinitiation should not exceed $5 \mathrm{~min}$ as the resin was found to be cross-linked beyond this amount of time. At the same time, the irradiation duration must be longer than $2 \mathrm{~min}$ so as to create enough active centers, enabling significant conversion through isothermal dark-curing (Figure 3). To increase the conversion rate of the epoxy, the photoinitiator content was increased while maintaining the duration of the irradiation step at $2.5 \mathrm{~min}$ to avoid gelification during the first step. As expected, increasing the iodine content improved the epoxy conversion, explained 
by the resultant increase in the amount of active centers in the first UV step (Figure 4). Additionally, increasing the duration of the thermal post-curing permitted to reach a conversion rate close to $80 \%$ with a photoinitiator content higher than $3 \mathrm{wt} . \%$. A quantity of $3.5 \mathrm{wt} . \%$ Iod was chosen for the rest of the study.

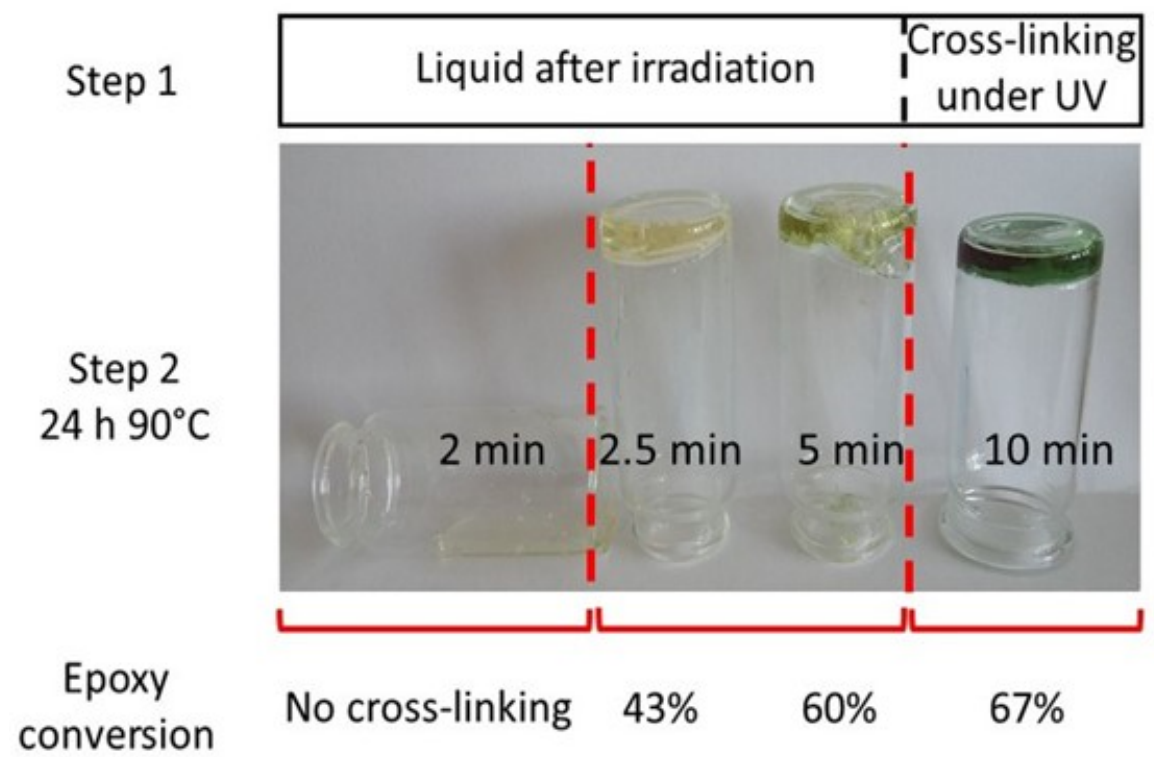

Figure 3. Photographs of the resins obtained with $1 \mathrm{wt} . \%$ Iod after various irradiation time and $24 \mathrm{~h}$ thermal treatment at $90{ }^{\circ} \mathrm{C}$.

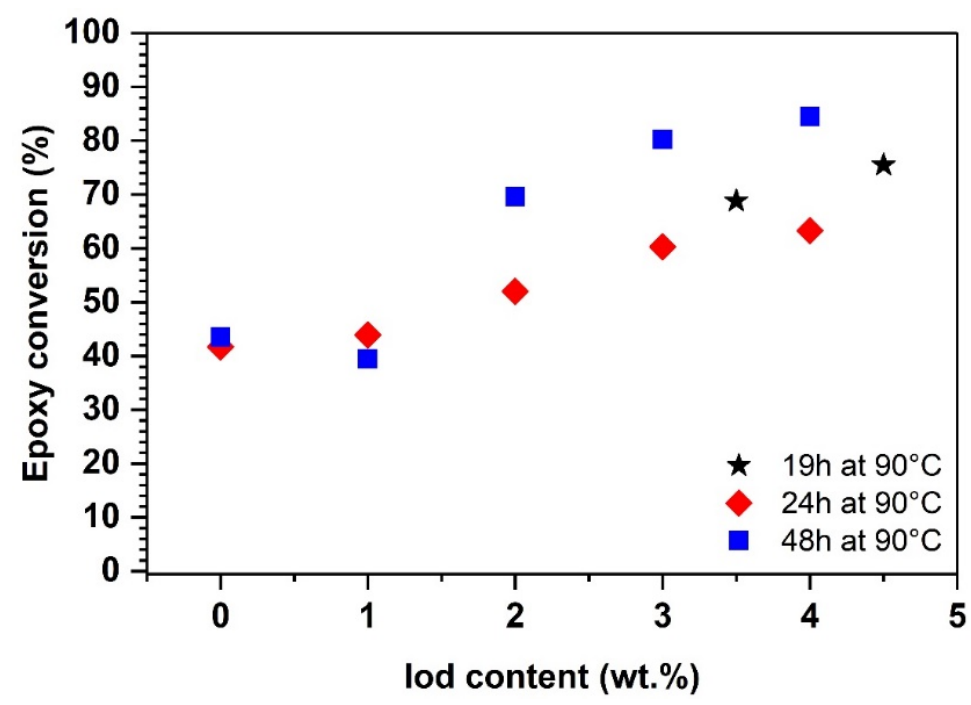

Figure 4. Influences of Iod content on the epoxy conversion of resins after 2.5 min irradiation and different thermal treatment conditions.

According to our previous study on photo-cross-linked bulk resins [24], a thermal postcuring at $130{ }^{\circ} \mathrm{C}$ (above the glass transition temperature $T_{g}$ ) led to complete conversion. In this work, we investigated the effect of the duration of the second step carried out at $130{ }^{\circ} \mathrm{C}$ on epoxy conversion (Figure 5). The post-thermal duration of $24 \mathrm{~h}$ at $130{ }^{\circ} \mathrm{C}$ was enough to achieve full epoxy group conversion. The preliminary study allowed to validate the two-step process whose optimal conditions are as follows: mixture of RDGE and $3.5 \mathrm{wt} . \%$ Iod irradiated for $2.5 \mathrm{~min}$, then a thermal post-curing at $130{ }^{\circ} \mathrm{C}$ for $24 \mathrm{~h}$. This optimal process opens the way to obtain full cross-linking of thick or opaque formulations. 


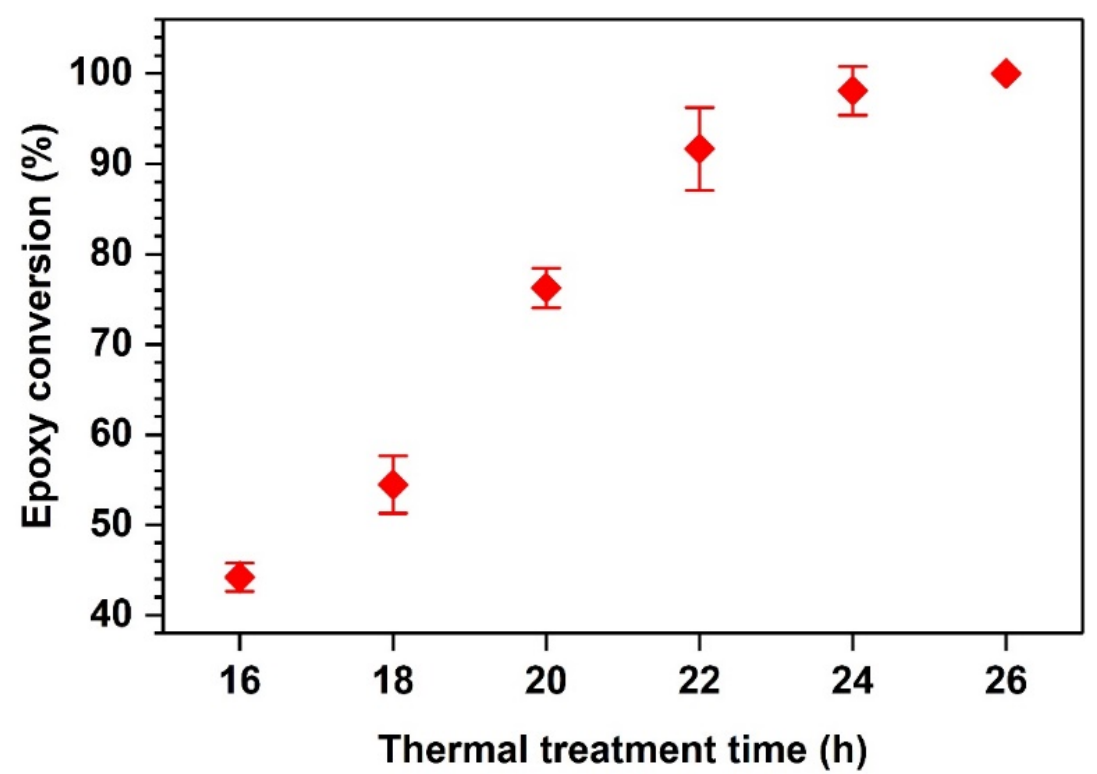

Figure 5. Influences of the duration of the thermal treatment conducted at $130{ }^{\circ} \mathrm{C}$ on the epoxy conversion of resins with $3.5 \mathrm{wt}$.\% Iod and $2.5 \mathrm{~min}$ irradiation.

\subsection{UV-Induced Epoxy-Diatomite Composites with Thermal Post-Curing}

Morphological and spectroscopic characterization of diatomite granules

The as-received diatomite granules were characterized by FTIR (Figure S1) and XRD (results not shown). The X-ray diffraction spectrum reveals the amorphous silica phase as the major phase. The amorphous state of the silica phase results from the calcination treatment carried out at a temperature lower than $1000^{\circ} \mathrm{C}$ [44].

The pore structure of diatomite was investigated by MIP and SEM. MIP results reveal heterogeneity in the pore size distribution. It can be seen in Figure 6 that the pore size varies from about 0.01 to $110 \mu \mathrm{m}$ with two major pore size populations centered around 0.01 and $3.3 \mu \mathrm{m}$. The average open porosity calculated from MIP analyses is $58 \%$. SEM images of the diatomite surface in Figure 7 also illustrate porous microstructures with agglomerated, irregular morphology, and various pore sizes. Additionally, fragments of diatom frustules, which are a biomass material derived from highly silicified cell walls of diatoms, are observed in this figure as well.

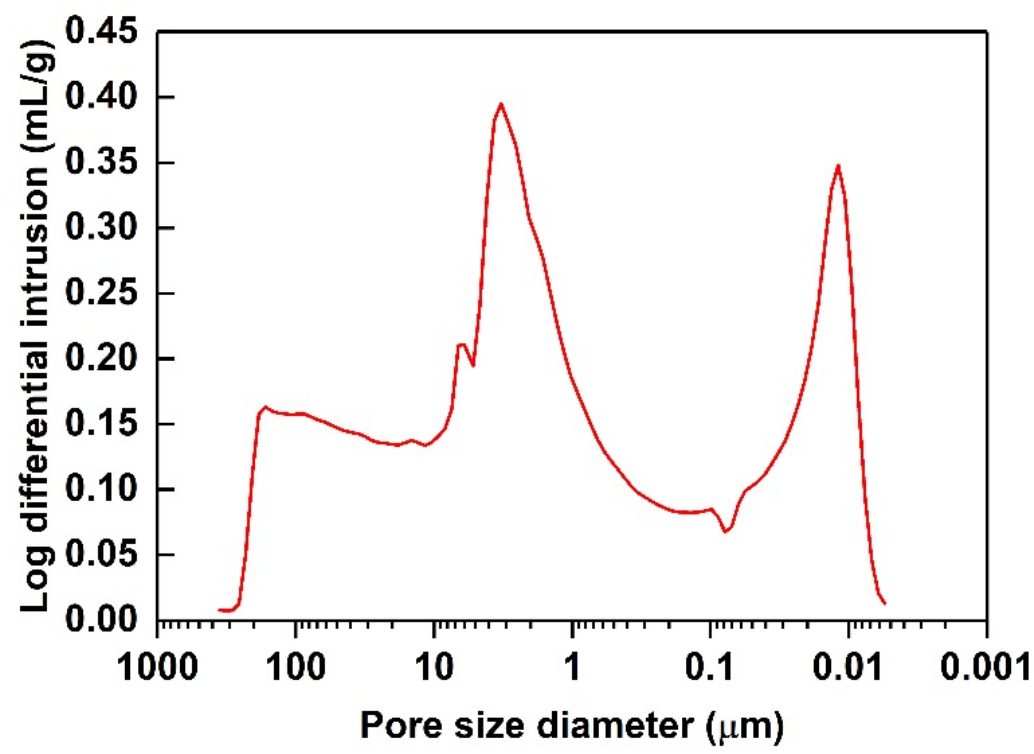

Figure 6. Mercury intrusion porosimetry (MIP) profile of the pore size distribution of diatomite. 

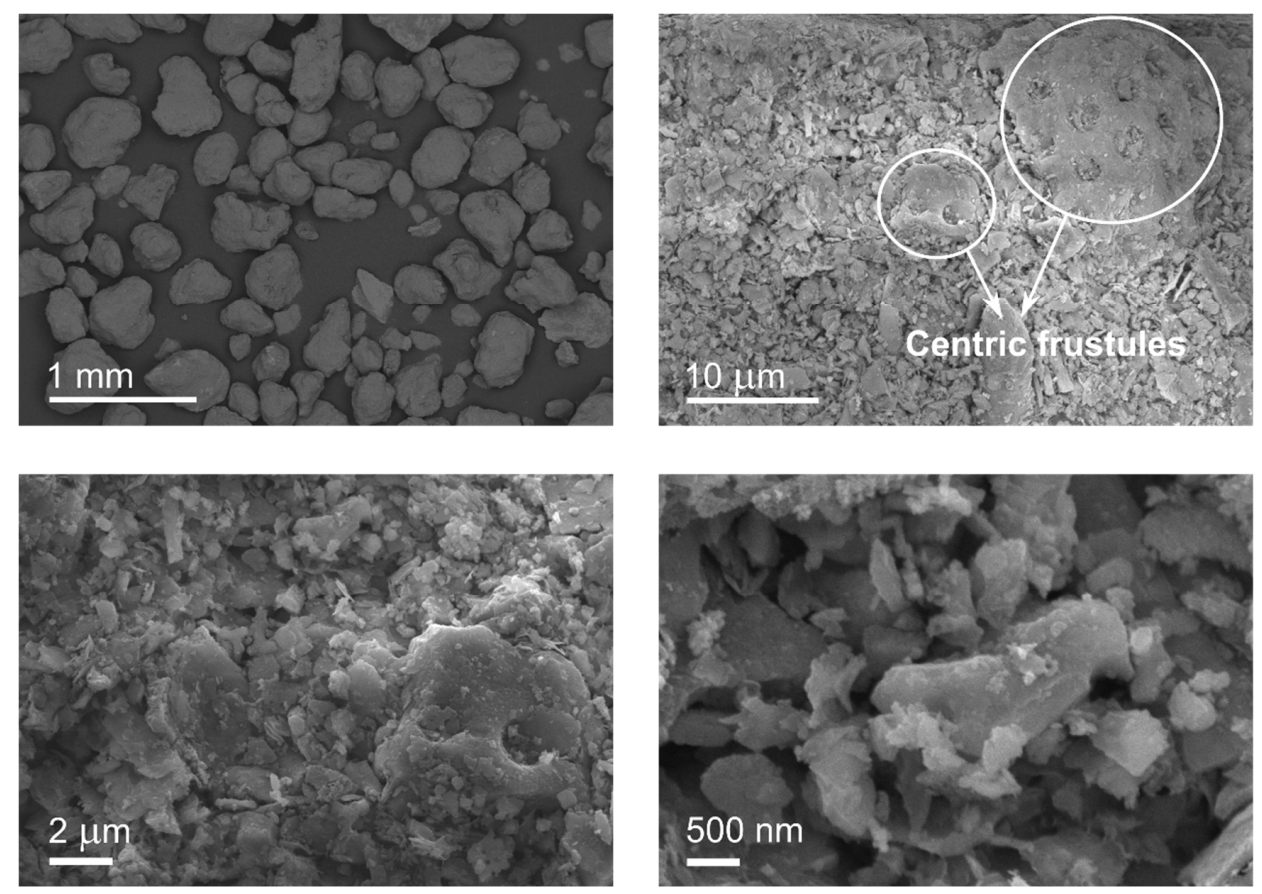

Figure 7. SEM images of the surface of as-received diatomite.

\subsection{RDGE Composites with Diatomite Granules: Effects of Diatomite Content}

Based on the optimal resin formulation previously determined, a series of composites consisting of such formulation with initial weight ratio of diatomite fillers from 30 to $60 \mathrm{wt} . \%$ with respect to the total weight of the composite formulation has been developed. The mixture of RDGE monomer and Iod photoinitiator was preliminarily irradiated under UV light for $2.5 \mathrm{~min}$ and then mixed with the diatomite. As mentioned before, mixing was carried out at room temperature to ensure a higher viscosity of the resin mixture, hindering its penetration into porous fillers. A compacting pressure of 3.9 MPa was applied to obtain a better homogeneous distribution of the epoxy formulation around the diatomite fillers. In addition, due to the thermal insulation properties of porous fillers, the second step, i.e., the thermal dark curing step, was prolonged to $48 \mathrm{~h}$ to achieve complete conversion of epoxy groups. The complete epoxy conversion was confirmed by DSC thermograms (Figure S2, Supplementary Material) which display that there are no exothermic peaks for both the pure resin and the composites. Figure 8 shows relatively homogeneous dispersion of diatomite particles within the epoxy matrix. Samples became darker with the increase in the RDGE content of the composite which gives a brownish color after thermal post-curing. The presence of holes on the sample surfaces is also noted and attributed to two reasons. The first reason is related to the composite formulation including a large amount of diatomite and accordingly a small amount of resin as in case of $60 \mathrm{wt} . \%$ diatomite. In this case, the resin content is insufficient to fill all of voids between diatomite granules, leading to the presence of mentioned holes. The second reason involves the elaboration processing. During the dark thermal curing, the resin is in the liquid state with less viscosity. Therefore, part of resin on the top of the sample tends to flow downwards, leaving holes on the top surface of the sample. Additionally, when a large amount of resin is used (cases of 30$50 \mathrm{wt} . \%$ diatomite), if the composite sample was left in the mold during the dark thermal curing, there would exist a layer of resin at the bottom of the sample (interface between the composite and the mold). The presence of such a resin layer on the one hand makes the obtained material be of sandwich type which is not the objective of the study, on the other hand weakens the sound absorption of the composite. In order to avoid this covering resin layer and make a rough surface for improving the sound absorption performance [45], the sample was unmolded before the dark thermal curing. As a consequence, during the 
thermal curing, part of resin on the bottom surface of the sample flowed out of the sample, generating holes on the bottom surface instead of the formation of a covering resin layer.

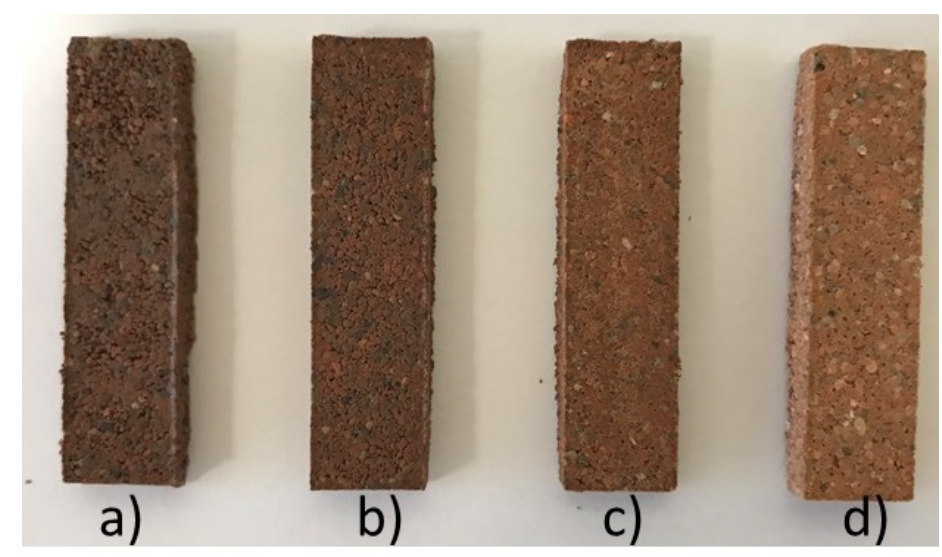

Figure 8. Photographs of epoxy RDGE-diatomite composite specimens with different diatomite weight ratio. Specimens were obtained with $3.5 \mathrm{wt}$ \% Iod, $2.5 \mathrm{~min}$ irradiation, 3.9 MPa compaction and $48 \mathrm{~h}$ thermal treatment at $130{ }^{\circ} \mathrm{C}$. (a) $30 \mathrm{wt.} \%$; (b) $40 \mathrm{wt.} \%$; (c) $50 \mathrm{wt.} \%$; (d) $60 \mathrm{wt.} \%$.

A deeper understanding of composites' morphology is achieved by studying the obtained SEM micrographs. In Figure 9, SEM images of external surfaces of composites with different diatomite contents are displayed. It can be seen that diatomite grains are well covered by the resin matrix for 30, 40, and $50 \mathrm{wt} . \%$ diatomite (Figure 9a-c), but not in case of $60 \mathrm{wt} . \%$ diatomite (Figure $9 \mathrm{~d}$ ). Indeed, a larger amount of filler in the latter case makes the resin not enough to cover diatomite grains in the composite. Moreover, still for the case of $60 \mathrm{wt} . \%$ diatomite, it can be seen that a considerable amount of pieces of diatomite has the size smaller than that of purchased diatomite granules ( $300 \mu \mathrm{m}$ minimum) as well as cracks on many larger grains (Figure 9d) are present in the samples. This phenomenon is attributed to the effect of the compaction during the elaboration process. When the filler content in composites increases, the impact of compaction loading becomes severer on diatomite granules, together with the fact that porous diatomite granules with porosity of $58 \%$ are fragile, causing damage to the grains, even breaking them into fragments.

Micrographs of fracture surfaces of composites after three-point bending tests are presented in Figure 10. It is noted that in case of 30, 40, and $50 \mathrm{wt} . \%$ diatomite, there exists great adhesion between the resin and diatomite grains, resulting partly from essential roughness of diatomite surfaces, and consequently one cannot observe any debonding of the matrix from the fillers. The composite failure mechanism is then related to the fracture of diatomite grains during mechanical loading. Another failure mechanism is found for the $60 \mathrm{wt} . \%$ diatomite composite. Its failure occurred around filler granules. As illustrated above, the use of a high diatomite content diminishes the amount of the resin around fillers, leading to the structure in which granules stick loosely together (Figure 10d). Under loading during three-point bending tests, these weak connections among diatomite grains tend to be damaged and to yield, causing the final failure of the composite with 60 wt. $\%$ diatomite. 
(a)

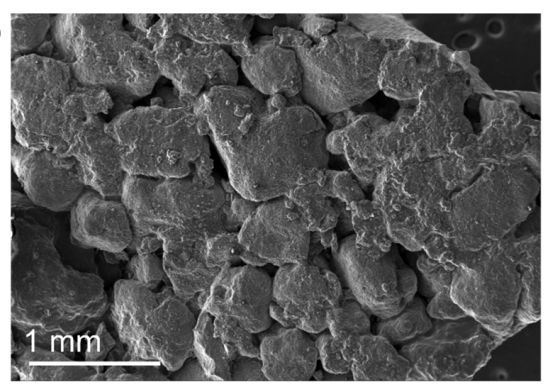

(b)

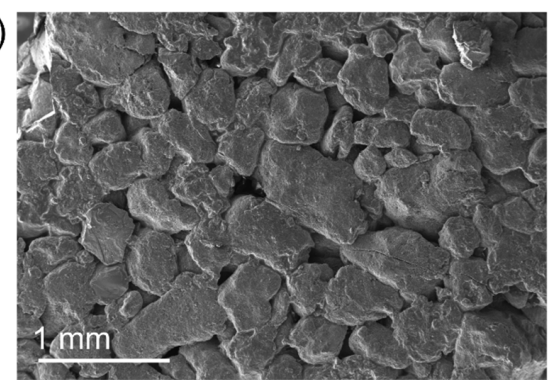

(c)

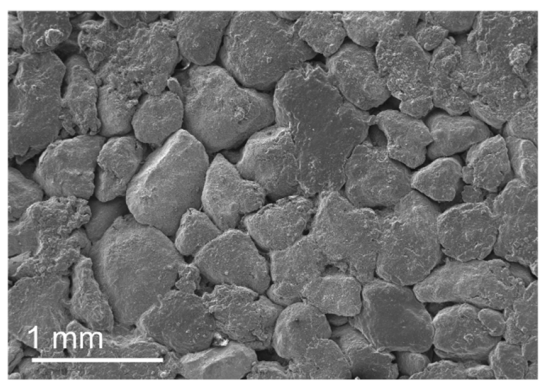

(d)

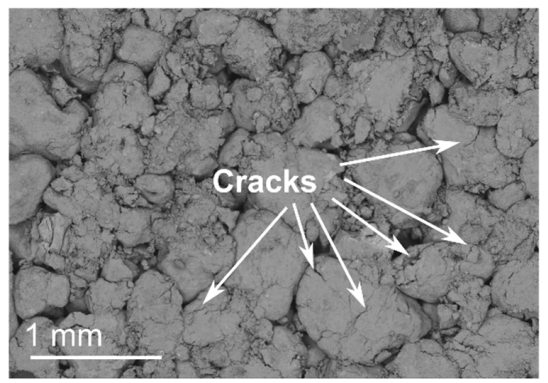

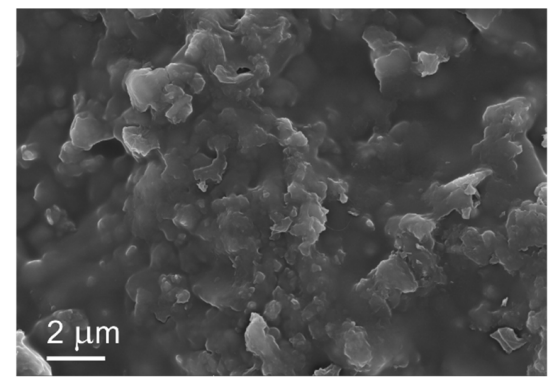
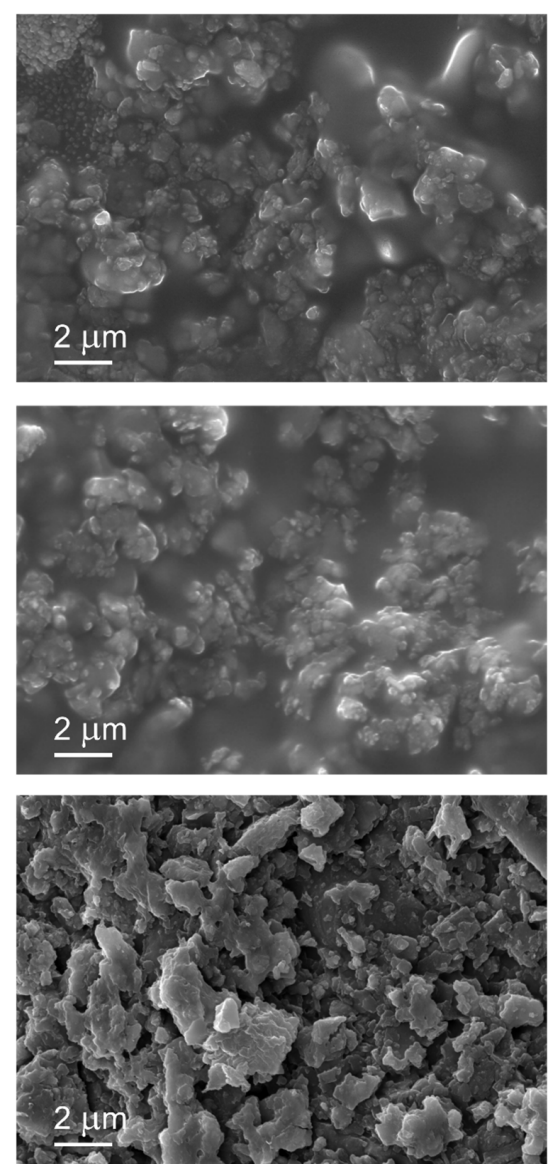

Figure 9. SEM micrographs of external surfaces of composites with different diatomite contents. The composites were obtained with $3.5 \mathrm{wt}$.\% Iod, $2.5 \mathrm{~min}$ irradiation, $3.9 \mathrm{MPa}$ compaction and $48 \mathrm{~h}$ thermal treatment at $130{ }^{\circ} \mathrm{C}$. (a) $30 \mathrm{wt} \%$; (b) $40 \mathrm{wt} \%$; (c) $50 \mathrm{wt.} \%$; (d) $60 \mathrm{wt} . \%$.

The influences of the diatomite content on the thermal properties were also investigated. As above-mentioned, DSC thermograms (Figure S2, Supplementary Material) show that there not exist exothermic peaks for the pure resin as well as for the composites, indicating complete conversion of epoxy groups. The glass transition temperatures $T_{g}$ of composites are about $50{ }^{\circ} \mathrm{C}$ lower than that of the pure epoxy resin as presented in Table 1 . This difference could be related to the thermal insulation properties of diatomite which have limited the diffusion of heat during polymerization, leading to faults in the polymeric network. Furthermore, a high diatomite content leads to dispersion of active molecules in the resin mixture, reducing reaction efficiency and consequently decreasing $T_{g}$ values of composites. However, it is noted that $T_{g}$ values of all composites under consideration are comparable to those of DGEBA-based composites with additives such as melamine, silica nanoparticles and a phosphorus-based compound developed for advanced thermo-mechanical and flame retardancy properties [47]. TGA was performed to study the influence of diatomite on the composite thermal decomposition. For pure 
diatomite, the char yield of $99 \mathrm{wt} . \%$ at $750{ }^{\circ} \mathrm{C}$ shows that siliceous diatomite is very stable at high temperature. A comparison of the char yield of the pure resin and those of composites (Table 1) indicates that diatomite contents in the obtained composites are slightly higher than the corresponding initial filler weight percentages, which is attributed to small resin loss during elaboration process. Indeed, during the elaboration of the composites, the compaction step with the application of a pressure to the composite formulation for attaining homogeneous distribution of the resin matrix around diatomite fillers was conducted. Because the resin mixture in the composite formulation was in the liquid state during this step, the compacting pressure made part of the resin mixture leave the mold, leading to the loss of resin and the decrease in resin amount in the final composites. As a consequence, the real weight percentage of diatomite fillers in the final composites, and accordingly the percentage of composite residues, became higher than the initial values of diatomite percentage. Nonetheless, it is worth noting that the loss of resin due to the compaction step is unavoidable (we can see the same phenomenon in, for example, the reference [48]). Figure 12 displays similar thermal decomposition profiles for the pure resin and composites with the diatomite content lower than $50 \mathrm{wt} . \%$. In addition, a high diatomite content induces a decrease in the initial decomposition temperature, suggesting that the epoxy network is less well cross-linked in case of a great amount of fillers, which is consistent with DSC analyses. Based on TGA results, calculations of the porosity of composites $\left(\phi_{1}\right)$ were undertaken (Equation (S3) in Supplementary Material). The porosity $\phi_{1}$ was calculated by noting that the microstructure of obtained composites is composed of three domains, namely resin, diatomite skeleton and pore domains. As mentioned above, the resin loss during composite processing lead to the change in weight percentages of the resin and diatomite components compared to their initial values. From TGA results, the weight percentages of these two components remaining in the final materials were calculated (Equations (S1) and (S2) in Supplementary Material). Knowing the total mass of final composites samples, true densities of resin as well as diatomite, and considering that the air mass is negligible, the masses and volumes of resin and diatomite skeleton domains were identified. The volume of the pore domain was then calculated by subtracting volumes of resin and diatomite skeleton domains from the total volume of composite samples, and finally the porosity $\phi_{1}$ was determined as the ratio of the pore volume to the total sample volume. The porosity $\phi_{1}$ calculated by the strategy above includes both intraparticle porosity (i.e., pores inside diatomite granules) and interparticle porosity (i.e., blank space or holes between granules) of the final materials. Note that the MIP analysis cannot be applied to determine the overall porosity of the studied composites because the fillers are well covered by the resin matrix and mercury cannot penetrate into the grains, missing the significant contribution of the intrapartile porosity to the overall porosity of composites. In addition to the porosity $\phi_{1}$, it is also worth calculating another porosity parameter denoted by $\phi_{2}$. This parameter corresponds to the composite porosity in idealized conditions that there is no loss of resin mixture during composite processing (i.e., the weight percentage of diatomite in final materials is the same as the initial value), and that the space among diatomite grains is filled completely by the resin and the resin does not penetrate into diatomite grains. As a consequence, only intraparticle porosity is present within the composite in this case and the porosity $\phi_{2}$ refers to this kind of porosity. The calculation of $\phi_{2}$ was performed with Equations (S4)-(S7) (see Supplementary Material), based on the same principle as in the calculation of $\phi_{1}$, that is, determining firstly masses and volumes of resin and diatomite skeleton domains, then calculating the pore volume with the use of porosity of diatomite $(58 \%)$, and finally taking the porosity $\phi_{2}$ as the ratio of the pore volume to the total sample volume. From calculated values of $\phi_{1}$ and $\phi_{2}$, it is noted that $\phi_{1}$ is lower than $\phi_{2}$ in case of 30,40 and $50 \mathrm{wt} . \%$ diatomite. This result is related to the noticeable penetration of resin into grains as shown in SEM images. For the composite with $60 \mathrm{wt} . \%$ diatomite, the high filler content restricts the matrix to penetrate into diatomite grains and also reduces the amount of resin around the grains, resulting in $\phi_{1}$ being higher than $\phi_{2}$. The incorporation of diatomite, which has a relatively high true 
density $\left(\rho_{d}=2.64 \mathrm{~g} / \mathrm{cm}^{3}\right)$, generally provokes the density of composites to become larger than that of the pure resin. However, the augmentation of the diatomite content leads to a decrease in the density of the composites, which can be explained by the increase in the overall porosity. In case of $60 \mathrm{wt} . \%$ diatomite, the density of the composite is even lower than that of the pure resin because of the considerable overall porosity of the composite induced by the significant reduction in the amount of the resin matrix around as well as inside diatomite grains as demonstrated in SEM images.

(a)
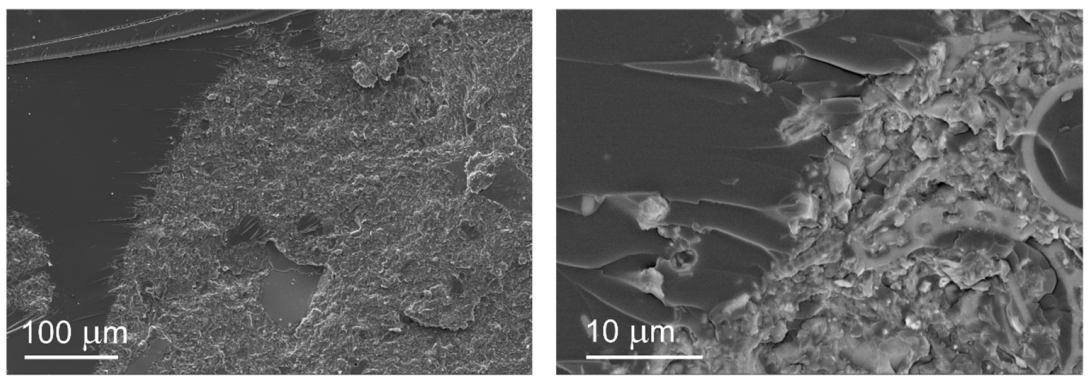

(b)
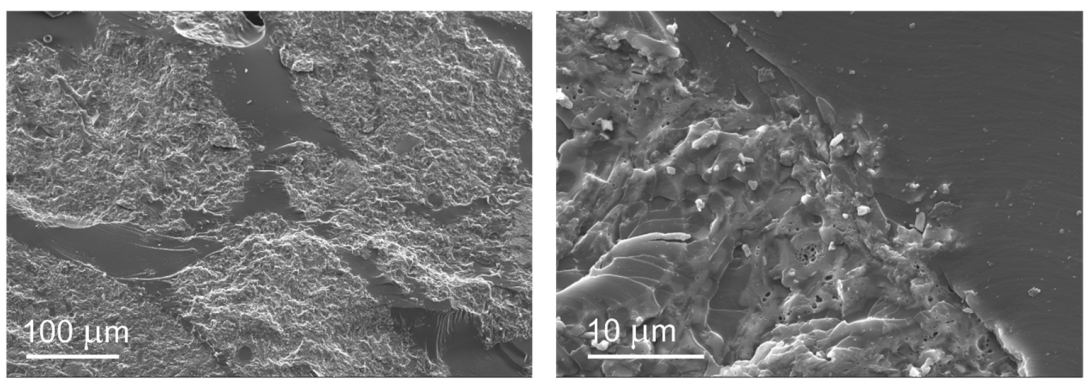

(c)
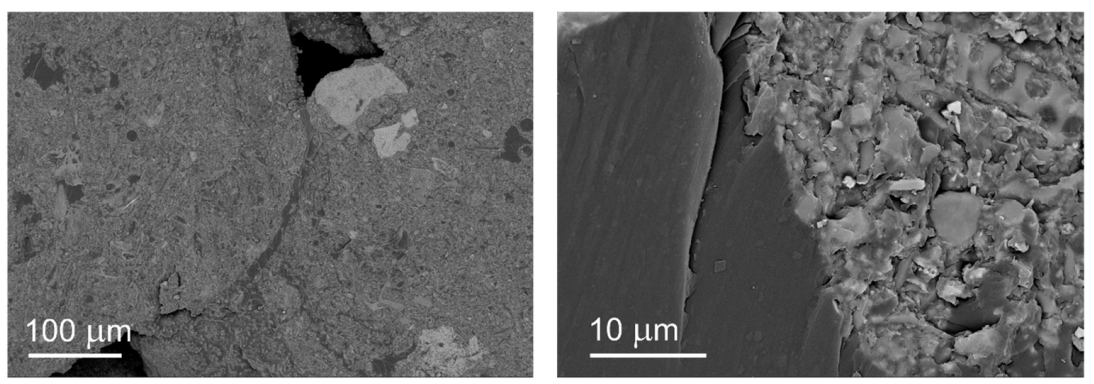

(d)
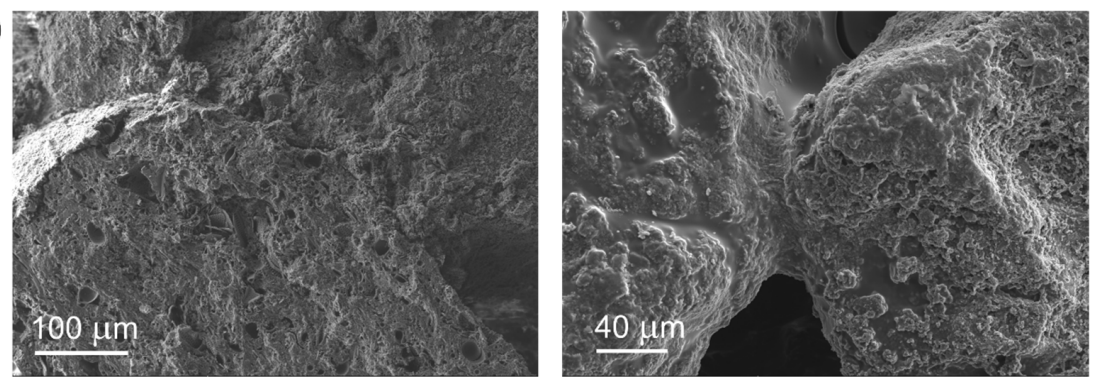

Figure 10. SEM micrographs of interfaces between the resin matrix and the fillers in composites with different diatomite contents. The composites were obtained with $3.5 \mathrm{wt} . \% \mathrm{Iod}, 2.5 \mathrm{~min}$ irradiation, $3.9 \mathrm{MPa}$ compaction and $48 \mathrm{~h}$ thermal treatment at $130^{\circ} \mathrm{C}$. (a) $30 \mathrm{wt} . \%$; (b) $40 \mathrm{wt} . \%$; (c) $50 \mathrm{wt} . \%$; (d) 60 wt. $\%$. 
(a)

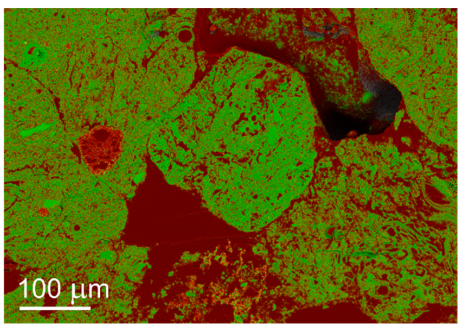

(c)

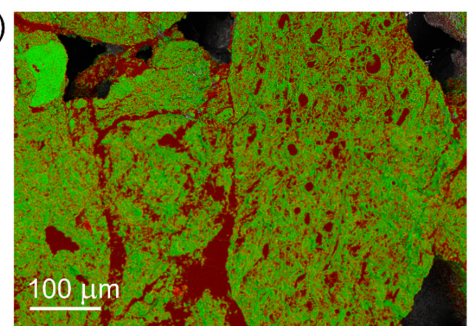

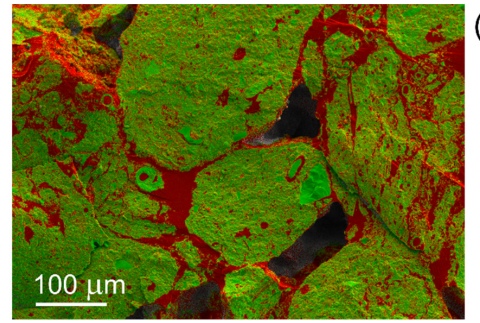

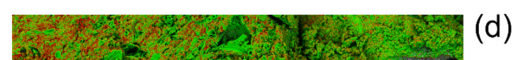

Figure 11. Energy dispersive X-ray (EDX) cartographs of fracture surfaces of composites with different diatomite contents. The composites were obtained with $3.5 \mathrm{wt} . \%$ Iod, $2.5 \mathrm{~min}$ irradiation, $3.9 \mathrm{MPa}$ compaction and $48 \mathrm{~h}$ thermal treatment at $130{ }^{\circ} \mathrm{C}$. The red and green colors signify respectively carbon and silicon elements. (a) $30 \mathrm{wt.} \%$; (b) 40 wt.\%; (c) 50 wt.\%; (d) 60 wt.\%.

Table 1. Thermal characteristic data collected from differential scanning calorimetry (DSC) and thermogravimetric analyses (TGA) analyses of the pure resin and composites.

\begin{tabular}{cccccc}
\hline $\begin{array}{c}\text { Diatomite Content } \\
\text { (wt.\%) }\end{array}$ & $\mathbf{0}$ & $\mathbf{3 0}$ & $\mathbf{4 0}$ & $\mathbf{5 0}$ & $\mathbf{6 0}$ \\
\hline$T_{g}\left({ }^{\circ} \mathrm{C}\right)$ & $153 \pm 3$ & $105 \pm 1$ & $100 \pm 1$ & $99 \pm 1$ & $96 \pm 1$ \\
$T_{5 \%}\left({ }^{\circ} \mathrm{C}\right)$ & 359 & 355 & 355 & 334 & 310 \\
$R_{750}(\mathrm{wt} . \%)$ & 6.5 & 47.0 & 53.5 & 57.5 & 71.4 \\
Calculated diatomite & - & 43.8 & 50.8 & 55.1 & 70.2 \\
cntent (wt.\%) & - & 17.5 & 19.3 & 24.2 & 41.9 \\
$\phi_{1}(\%)^{*}$ & - & 19.6 & 25.6 & 31.5 & 37.2 \\
$\phi_{2}(\%) *$ & 1.318 & 1.437 & 1.427 & 1.380 & 1.181 \\
\hline Density $\left(\mathbf{g} / \mathrm{cm}^{3}\right)$ & & & & \\
\hline
\end{tabular}

$T_{5 \%}$ : temperature at which the weight loss is $5 \% . R_{750}$ : residual weight at $750{ }^{\circ} \mathrm{C} .{ }^{*}$ Details of calculations are described in Supplementary Material.

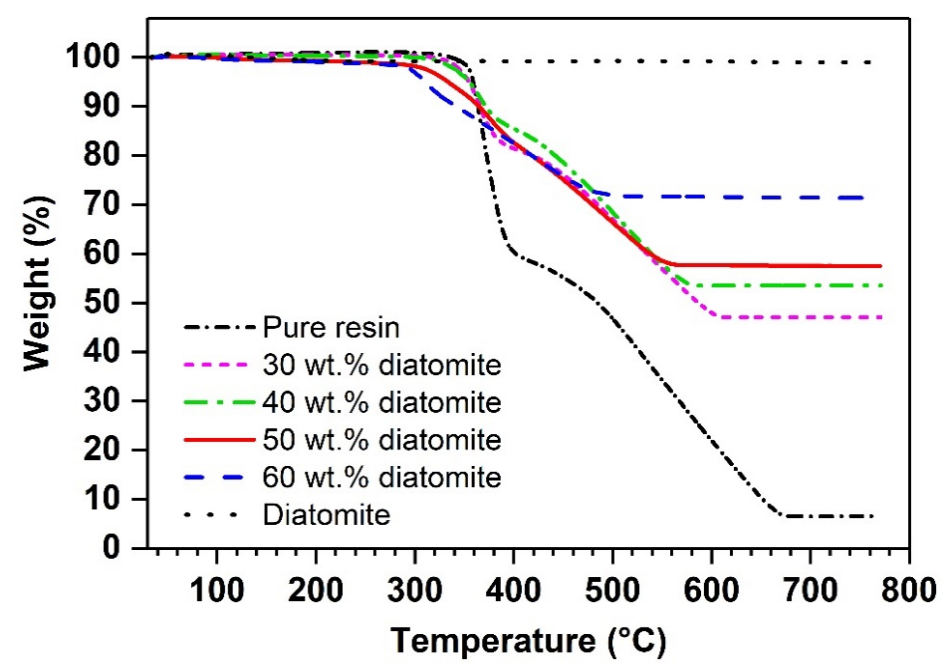

Figure 12. TGA thermograms (under air) of the pure resin, diatomite and composites with different diatomite contents. The composites were obtained with $3.5 \mathrm{wt} . \%$ Iod, $2.5 \mathrm{~min}$ irradiation, $3.9 \mathrm{MPa}$ compaction, and $48 \mathrm{~h}$ thermal treatment at $130^{\circ} \mathrm{C}$. 
The mechanical behavior of the composites with different diatomite contents is of interest as well. Figure 13 shows the flexural modulus and the flexural strength of such composites as functions of the diatomite content. It can be seen in Figure 13 that, while the flexural modulus is enhanced for composites with up to $50 \mathrm{wt} . \%$ diatomite, the flexural strength is degraded for all composite formulations in comparison with that of the pure resin. This degradation of the flexural strength is noticeably associated with the presence of voids in the composite structures building up the porosity of at least about $16 \%$. When the diatomite weight percentage is increased, reductions in the flexural modulus and the flexural strength are observed. This trend is accounted for mainly by the increase in the overall composite porosity. In addition, there exists an auxiliary reason which is the faults in the polymeric network resulting from the restriction of heat diffusion and of dispersion of reactive molecules during polymerization due to large amounts of diatomite. Particularly, the use of $60 \mathrm{wt} . \%$ diatomite induces sharp drops in both flexural properties (reductions by factors of three and seven in respectively the flexural modulus and the flexural strength compared to those of the composite with $50 \mathrm{wt} . \%$ diatomite). This phenomenon is attributed to the substantial increase in the porosity of the composite (from $22 \%$ porosity in case of $50 \mathrm{wt} . \%$ diatomite to $40 \%$ porosity with $60 \mathrm{wt} . \%$ diatomite) and to also the change in the failure mechanism as shown in SEM analyses. While the failure of composites was induced by the fracture of filler grains in case of 30, 40, and $50 \mathrm{wt} . \%$ diatomite, the applied bending load tended to break weak connections among filler granules, leading to the undemanding failure of the composite with $60 \mathrm{wt} . \%$ diatomite. It is worth noting that the mechanical properties of composites with 30,40 , and $50 \mathrm{wt} . \%$ diatomite are comparable to those of porous silicon carbide ceramics [49] as well as high performance DGEBA-based composites, including melamine, silica nanoparticles, or a phosphorus-based compound as additives [47]; particularly, the studied composites exhibits mechanical properties notably superior to those of various commercial polymeric foams such as polyurethane [50], polyimide [51], and epoxy [48] foams.

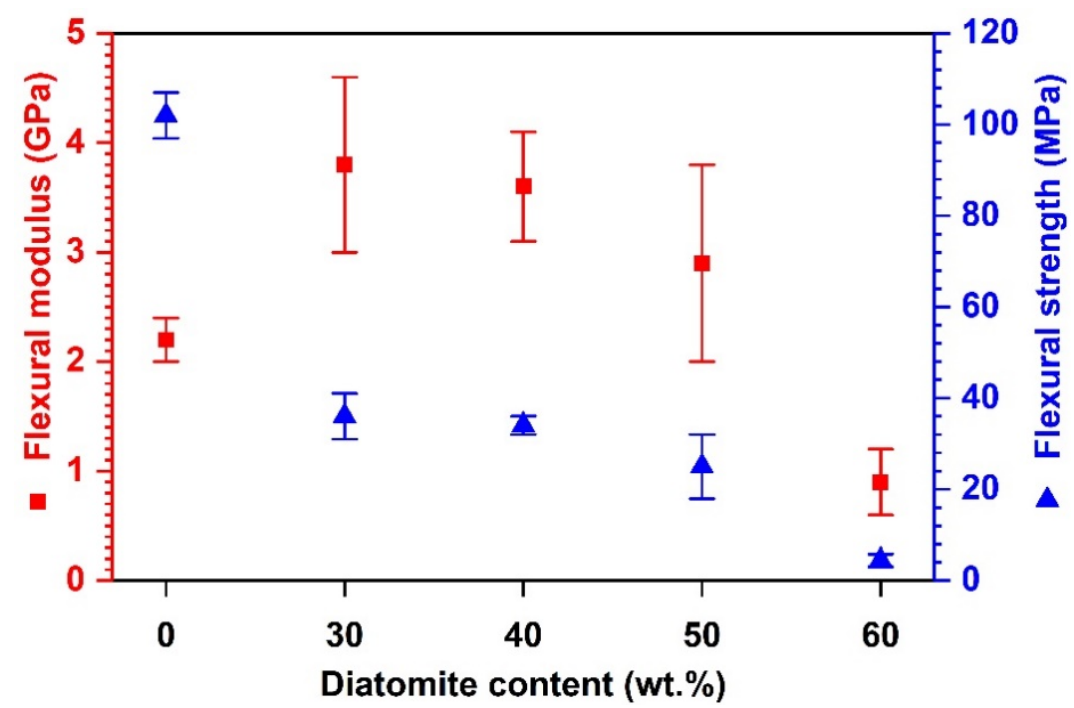

Figure 13. Flexural properties of the pure resin and composites with different diatomite contents. The composites were obtained with $3.5 \mathrm{wt}$.\% Iod, $2.5 \mathrm{~min}$ irradiation, $3.9 \mathrm{MPa}$ compaction, and $48 \mathrm{~h}$ thermal treatment at $130{ }^{\circ} \mathrm{C}$.

The effects of diatomite content on the sound absorption performance of composites were further studied. Figure 14 displays the measurements of sound absorption coefficients of the pure resin and composites with different diatomite contents. The pure resin exhibits weak absorption effect with MSAA $=0.01$. Indeed, as a non-porous material, the pure resin reflects rather than absorbs incoming sound waves. As expected, the use of diatomite fillers helps to enhance sound absorption performance as seen in Figure 14. It was determined that 
the more diatomite content used in the formulation, the higher sound absorption capacity of the composite. The improvement of the sound absorption performance of composites is quantified by MSAA values which are $0.03,0.04,0.08$, and 0.10 for composites with respectively 30, 40, 50, and $60 \mathrm{wt} . \%$ diatomite. Accordingly, a notable rise by a factor of two in the MSAA is recorded when increasing the diatomite content from 40 to $50 \mathrm{wt} . \%$. It can be noted that the MSAA values obtained with $5 \mathrm{~mm}$ thick samples of 50 and $60 \mathrm{wt} . \%$ diatomite composites are promising results for the development of construction materials absorbing sound waves at low frequencies. Indeed, the use of 50 and $60 \mathrm{wt} . \%$ diatomite on the one hand leads to considerable overall porosities. On the other hand, it generates microstructures possessing agglomerated, irregular morphology with the presence of both interparticle and intraparticle voids, resulting in higher tortuosity and resistivity of the composites compared to those with a lower diatomite content. Due to these two advantages, it was demonstrated herein that the composites with 50 and $60 \mathrm{wt} . \%$ diatomite exhibit impressive sound absorption performances at low frequencies.

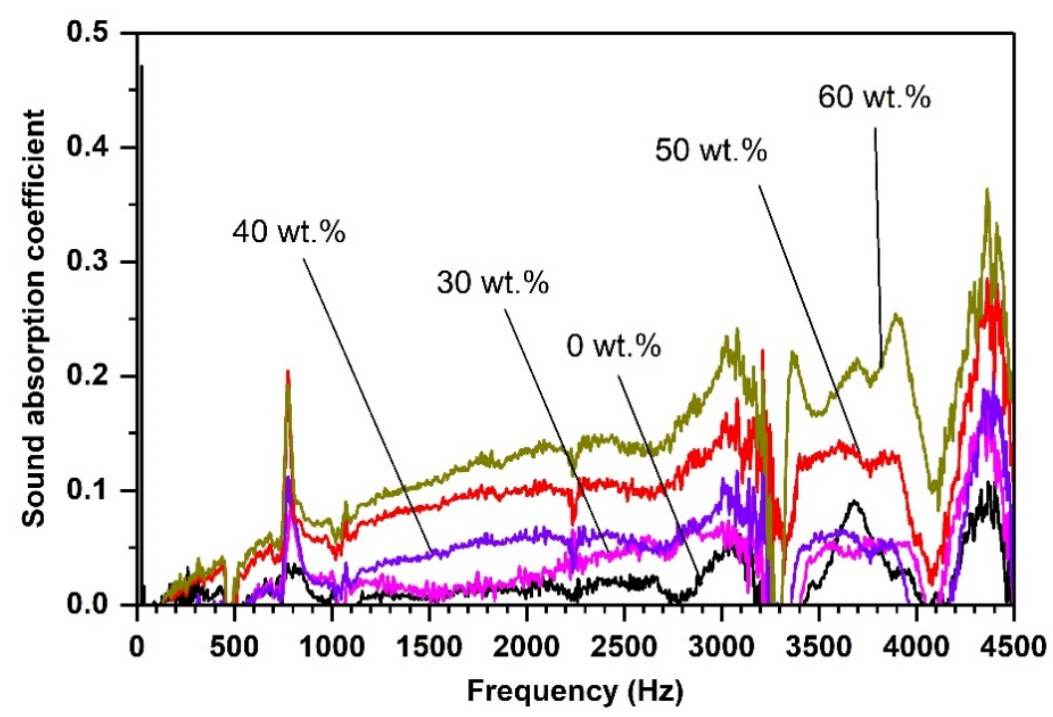

Figure 14. Normal incidence sound absorption coefficients of the pure resin and composites with different diatomite contents. The samples have a thickness of $5 \mathrm{~mm}$. The composites were obtained with $3.5 \mathrm{wt}$ \% Iod, $2.5 \mathrm{~min}$ irradiation, $3.9 \mathrm{MPa}$ compaction, and $48 \mathrm{~h}$ thermal treatment at $130{ }^{\circ} \mathrm{C}$.

The flammability behavior of all material samples was investigated using pyrolysis combustion flow calorimetry (PCFC) [52] tests, according to ASTM D7309 [53]. The heat release rate (HRR) curve of diatomite displayed in Figure S3 (Supplementary Material) reveals its practically null contribution to flammability. This means that flammability of the epoxy resin matrix is responsible for overall flammability of studied composites. The HRR curves of the pure resin and composite samples with different diatomite contents are presented in Figure 15 and the collected data are summarized in Table 2. It can be observed in Figure 15 that all samples generally present one peak of HRR (pHRR), showing the homogeneity of the resin matrix. The existence of a small shoulder at higher temperature than that of the main $\mathrm{pHRR}$ for the curve of the pure resin sample corresponds to the degradation of char residues formed previously. For the pure resin sample, the peak of $487 \mathrm{~W} / \mathrm{g}$ occurs at $384{ }^{\circ} \mathrm{C}$. In the presence of diatomite, the peak is shifted to higher temperature, except for the $30 \mathrm{wt} . \%$ diatomite sample. A sharp drop of $\mathrm{pHRR}$ is observed for all composite samples, with respect to that of the pure resin. Thus, the $\mathrm{pHRR}$ is $129 \mathrm{~W} / \mathrm{g}, 132 \mathrm{~W} / \mathrm{g}, 109 \mathrm{~W} / \mathrm{g}$ and $97 \mathrm{~W} / \mathrm{g}$ respectively for 30, 40, 50, and $60 \mathrm{wt} . \%$ diatomite samples. Total heat release (THR) values were calculated by the integration of HRR curves. It is shown that the THR value also considerably decreases from $16.2 \mathrm{~kJ} / \mathrm{g}$ for the pure resin to $5.7 \mathrm{~kJ} / \mathrm{g}, 6 \mathrm{~kJ} / \mathrm{g}, 5 \mathrm{~kJ} / \mathrm{g}$ and $4.4 \mathrm{~kJ} / \mathrm{g}$, respectively, for 30, 40, 50, and $60 \mathrm{wt} . \%$ diatomite samples. For both pHRR and THR, a decreasing trend is generally 
observed with respect to the increase of the diatomite content. From similar values for 30 and $40 \mathrm{wt} . \%$ diatomite samples, noticeable reductions in pHRR and THR are perceived when using higher diatomite contents. The significant reductions in PHRR and THR of composite samples compared with those of the pure resin are attributed, on the one hand, to the fact that the flammable contents (i.e., resin contents) of composite samples are much less than that of the pure resin. On the other hand, the diffusion of the resin matrix between and inside excellently thermally resistant diatomite grains favors the protection of the resin against the flame, hence reducing both pHRR and THR. In comparison with high performance polymers such as poly(ether ether ketone) (PEEK) which possesses a pHRR of around $200 \mathrm{~W} / \mathrm{g}[54,55]$ or polyimide (PI) with a pHRR of about $260 \mathrm{~W} / \mathrm{g}$ [56], it is clear that the studied epoxy-diatomite composite samples exhibit a satisfying flame retardancy behavior.

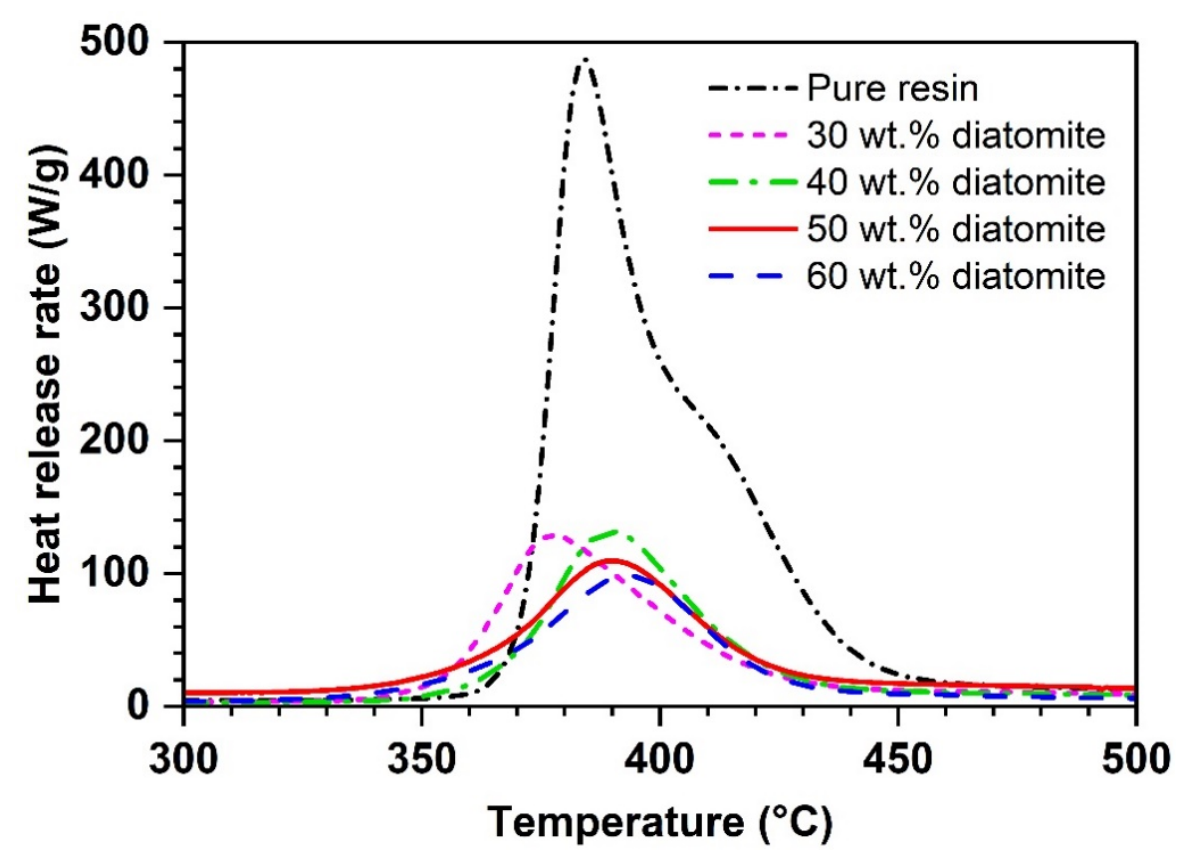

Figure 15. Heat release rate (HRR) curves obtained in pyrolysis combustion flow calorimeter (PCFC) tests for the pure resin and 30-60 wt.\% diatomite samples. The composites were obtained with $3.5 \mathrm{wt}$.\% Iod, $2.5 \mathrm{~min}$ irradiation, $3.9 \mathrm{MPa}$ compaction, and $48 \mathrm{~h}$ thermal treatment at $130{ }^{\circ} \mathrm{C}$.

Table 2. Summary results obtained in PCFC tests for the pure resin and 30-60 wt.\% diatomite samples. The composites were obtained with $3.5 \mathrm{wt}$.\% Iod, $2.5 \mathrm{~min}$ irradiation, $3.9 \mathrm{MPa}$ compaction, and $48 \mathrm{~h}$ thermal treatment at $130{ }^{\circ} \mathrm{C}$.

\begin{tabular}{cccc}
\hline Diatomite Content (wt.\%) & pHRR (W/g) & T $_{\mathbf{p H R R}}\left({ }^{\circ} \mathbf{C}\right)$ & THR $\mathbf{~ ( k J / g ) ~}$ \\
\hline 0 & 487 & 384 & 16.2 \\
30 & 129 & 377 & 5.7 \\
40 & 132 & 390 & 6 \\
50 & 109 & 390 & 5 \\
60 & 97 & 394 & 4.4 \\
\hline
\end{tabular}

Since PCFC is not considered as a real flame test, the real flame behavior of samples with different diatomite contents was examined using a vertical burning test (Figure 2). Two series of tests were performed. For the first series, the Bunsen burner flame was applied during $3 \mathrm{~s}$ and then moved up to observe the apparition of a clear flame. This operation was repeated in case of absence of flame on sample. It was observed that for the pure resin the inflammation was easier, whereas for all composite samples it was needed to apply the Bunsen burner flame many times to have a flame on each composite 
sample (Videos S1-S5, Supplementary Material). Even when a flame appeared, after the ignition source was removed, it went out after several seconds in case of a small flame. All of these thing indicate that the studied composites display self-extinguishing property in case of short ignition time. Nevertheless, when a large enough flame appeared (after many times of the Bunsen burner application or a long ignition time), the flame tended to propagate on the sample surfaces by burning resin matrix, showing that the composites did not exhibit the self-extinguishing anymore.

In the second series of tests, the Bunsen burner flame was applied for $9 \mathrm{~s}$ in order to have a flame on each sample. The photographs of flame tests as a function of burning time are presented in Figure 16 to clarify the effect of diatomite on flame retardancy. Figure 16 clearly shows the size of flames during the tests for all samples. When the pure resin sample was ignited, a big flame immediately appeared and continued until the flame out. A smaller flame height was observed for all composite samples compared with that for the pure resin. Overall, the best behavior was observed in case of $60 \mathrm{wt} . \%$ diatomite with the smallest flame within the shortest time of burning and flame out. It is also noted that the pure resin sample exhibited a high shrinkage during the test, whereas no shrinkage was observed for the composite samples. In addition, for all samples, no dripping behavior was observed and at the end of the tests large quantities of residues were obtained (Figure 17). Particularly, the residue of the pure resin sample was brittle, whereas those of composite samples were interestingly highly cohesive, which is an important feature related to the flame resistance character [57]. The fact that the composite residues were highly cohesive justifies that not all of resin was burned out. The cohesion observed here is obviously not the result of burning diatomite but is the characteristic of the residues of burnt resin. If the resin was burnt totally, its residues would be brittle char instead of cohesive products. The presence of cohesive products in this case is explained by the fact that sintered diatomite grains with their highly thermal insulation property behaved as thermal barriers protecting the resin component and reducing thermal effect of the flame on this component, particularly for part of resin far from the sample surfaces. Therefore, only resin on or near the sample surfaces was burnt completely, whereas the remaining resin turned into an intermediate state with the cohesive characteristic. It is also seen that the cohesion of these composite residues became more important with respect to the increase in the diatomite content. Indeed, not only the flame retardancy characteristic but also the flame resistance behavior and hence the structural integrity, which is involved in mechanical properties of composites during combustion, is a key feature offering the possibility of using these epoxy-diatomite composites in construction and building applications. Nonetheless, in order to obtaining such a characteristic, an appropriate diatomite content is required. If there is too little diatomite, a major part of resin will be exposed to the flame and burnt completely. Conversely, if there are too much diatomite, the resin content will not be enough to bond diatomite granules after burning process.

Towards the development of sound absorbing and flame-retardant construction materials, the mechanical properties, the acoustic performance and the flammability behavior of composites need to be all considered. The enhancement of the sound absorption performance and the flammability behavior comes at the cost of degrading the material mechanical properties. Although the composite with $60 \mathrm{wt} . \%$ diatomite displays the best sound absorption performance and the best flammability behavior among the studied composites, a significant drop in its flexural properties compared to those of other composites is recorded. On the contrary, although 30 and $40 \mathrm{wt} . \%$ diatomite composites possess good flexural modulus, their sound absorption capacities are much more restricted than that of two other composites. Taking into account a compromise among mechanical properties, acoustic characteristics and the flammability behavior, the diatomite content of $50 \mathrm{wt} . \%$ can be considered the optimal value in this work for the attainment of a composite with good mechanical properties, a good sound absorption performance and a satisfying flammability behavior. 


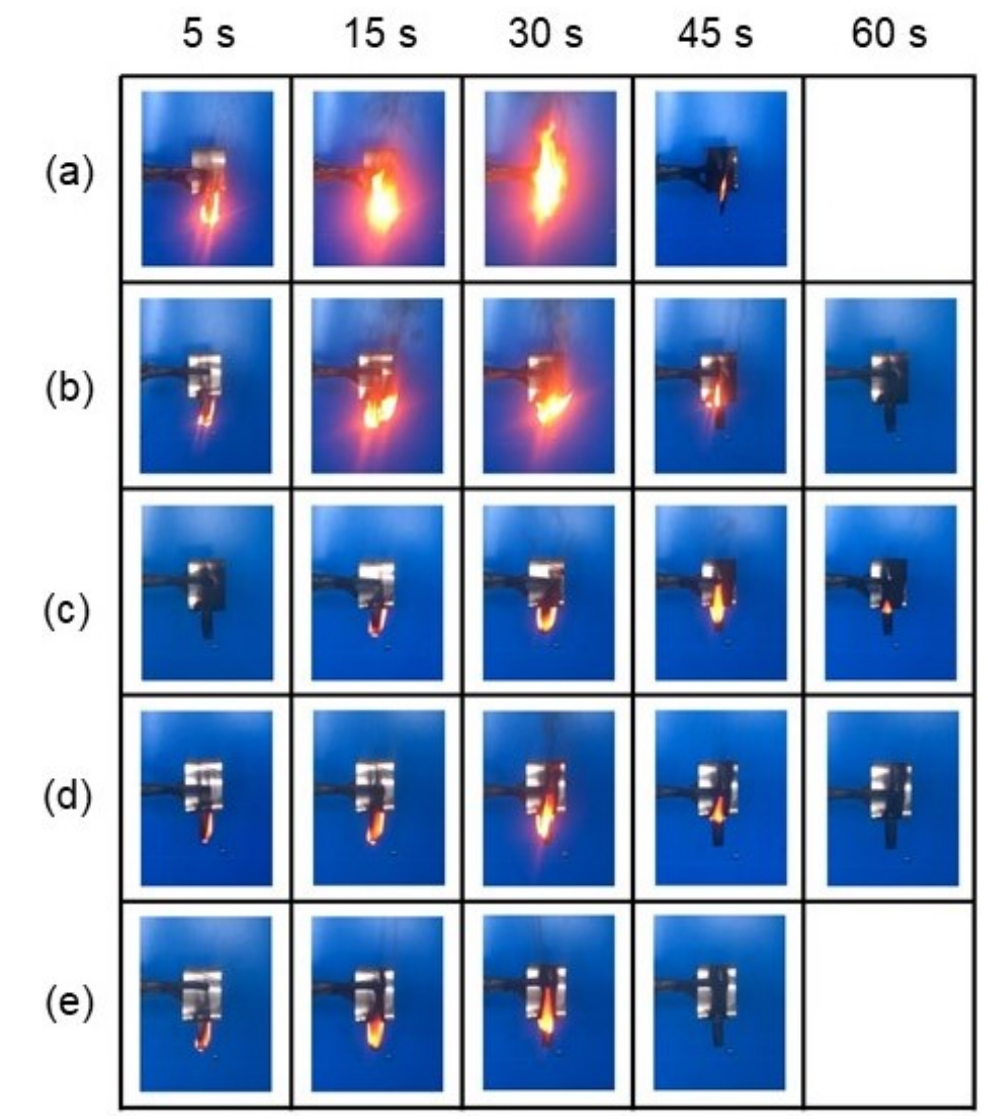

Figure 16. Digital photos showing the examination of the flame behavior during the vertical flame tests for the pure resin and composite samples with different diatomite contents. The Bunsen burner flame was applied for $9 \mathrm{~s}$. The composites were obtained with $3.5 \mathrm{wt}$ \% Iod, $2.5 \mathrm{~min}$ irradiation, 3.9 $\mathrm{MPa}$ compaction and $48 \mathrm{~h}$ thermal treatment at $130{ }^{\circ} \mathrm{C}$. (a) Pure resin, (b) $30 \mathrm{wt} . \%$ diatomite; (c) 40 wt.\% diatomite; (d) 50 wt.\% diatomite; (e) 60 wt.\% diatomite.

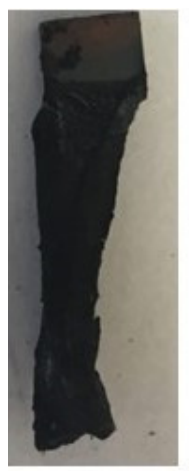

(a)

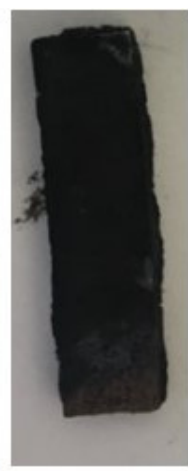

(b)

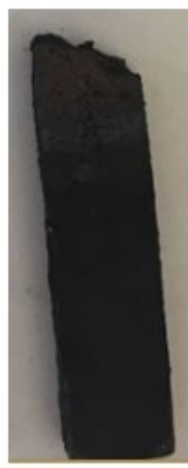

(c)

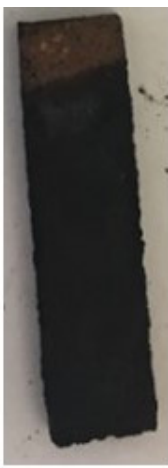

(d)

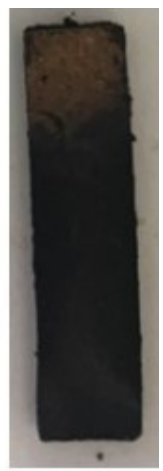

(e)

Figure 17. Digital photos of the residues of the pure resin and composite samples with different diatomite contents at the end of flame tests. The Bunsen burner flame was applied for $9 \mathrm{~s}$. The composites were obtained with $3.5 \mathrm{wt}$. $\%$ Iod, $2.5 \mathrm{~min}$ irradiation, $3.9 \mathrm{MPa}$ compaction and $48 \mathrm{~h}$ thermal treatment at $130{ }^{\circ} \mathrm{C}$. (a) Pure resin, (b) $30 \mathrm{wt} . \%$ diatomite; (c) $40 \mathrm{wt} . \%$ diatomite; (d) $50 \mathrm{wt} . \%$ diatomite; (e) $60 \mathrm{wt} . \%$ diatomite.

\section{Effects of Compacting Pressure}

In addition to the diatomite content, the compacting pressure is also a key parameter influencing the obtained composites' behavior. In order to determine the optimal compacting pressure, $50 \mathrm{wt}$ \% diatomite formulations were compacted under pressures of 1.95, 
3.9, and 5.85 MPa. It was found that, the porosity decreases with increasing compacting pressure (Figure 18) due to more compact packing of diatomite grains and better filling of both intraparticle and interparticle voids by the resin. At the same time, the residual percentage increases accordingly because of more loss of the resin mixture during compaction and the rising composite compactness. The decrease of the porosity is also the reason for the improvement of both flexural modulus and flexural strength of the composite when increasing the compacting pressure as seen in Figure 19. Although the flexural properties of the composite are enhanced, the increase in the compacting pressure lessens the sound absorption performance of the composite (Figure 20). While raising the compacting pressure from 1.95 to $3.9 \mathrm{MPa}$ leads to a merely slight reduction in the MSAA (from 1.0 to 0.08 ), a significant drop of this single-number rating from 0.8 down to 0.03 is observed for a rise of the pressure from 3.9 to $5.85 \mathrm{MPa}$. It is obvious that the deterioration of the sound absorption performance of the composite is associated with the decrease of the porosity when augmenting the compacting pressure. The less porosity or more compactness of the composite, the more reflection rather than absorption capacity of the material. The effect of compacting pressure on flammability was also evaluated in PCFC analyses. The results showed that the HRR curves of $50 \mathrm{wt} . \%$ diatomite composites compacted under 1.95, 3.9, and $5.85 \mathrm{MPa}$ are similar (Figure S4, Supplementary Material), meaning that the variation of compacting pressure has no much influence on composite flammability. By considering both flexural and acoustic properties as well as the flammability behavior, the value of 3.9 $\mathrm{MPa}$ can be considered as the optimal compacting pressure for the elaboration process of the studied composites.

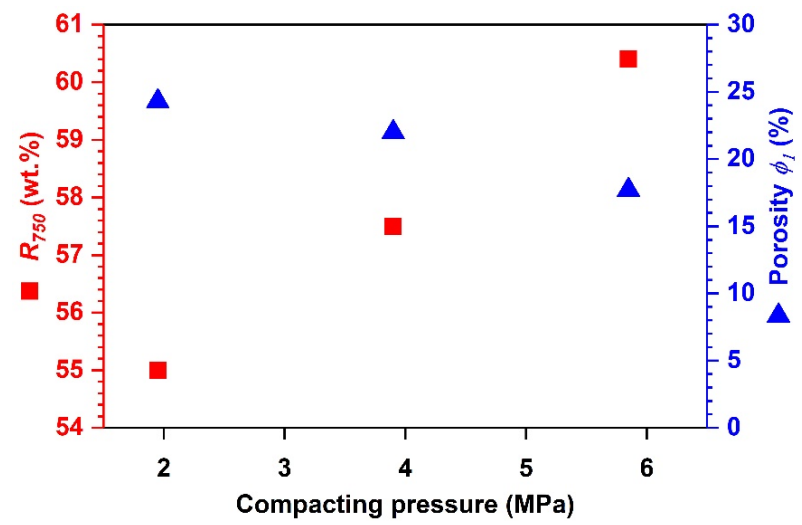

Figure 18. The residue at $750{ }^{\circ} \mathrm{C}$ and the porosity of the composite with $50 \mathrm{wt} . \%$ diatomite as a function of the compacting pressure.

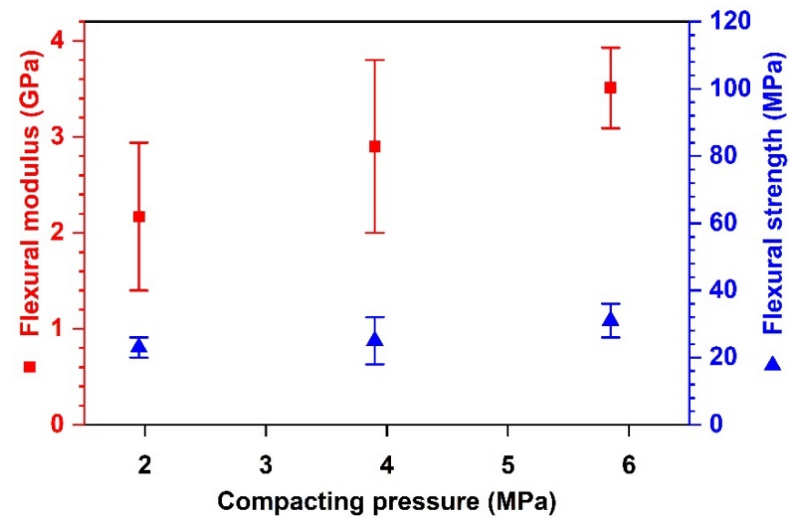

Figure 19. Flexural properties of composites with different compacting pressures. The composites were obtained with $50 \mathrm{wt} . \%$ diatomite, $3.5 \mathrm{wt} . \%$ Iod, $2.5 \mathrm{~min}$ irradiation, and $48 \mathrm{~h}$ thermal treatment at $130{ }^{\circ} \mathrm{C}$. 


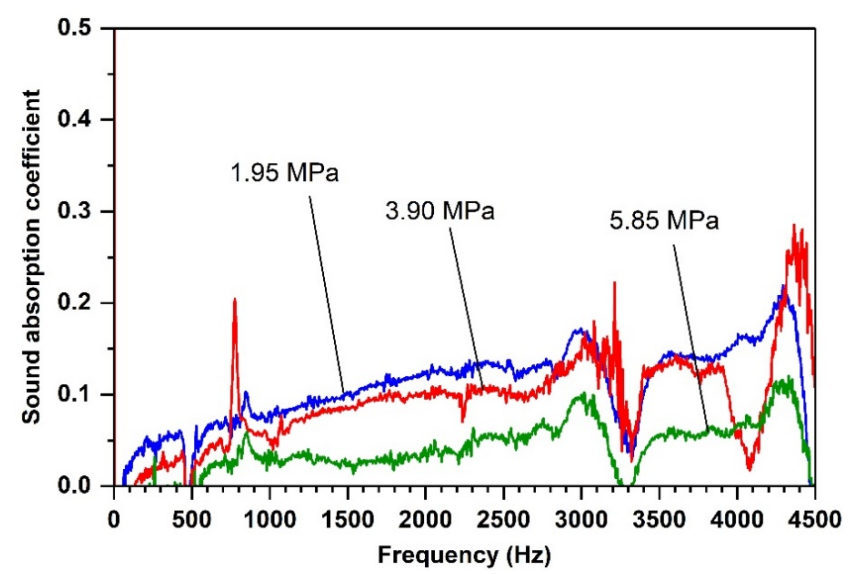

Figure 20. Normal incidence sound absorption coefficients of composites with different compacting pressures. The thickness of samples is $5 \mathrm{~mm}$. The composites were obtained with $50 \mathrm{wt} . \%$ diatomite, $3.5 \mathrm{wt} . \%$ Iod, $2.5 \mathrm{~min}$ irradiation, and $48 \mathrm{~h}$ thermal treatment at $130{ }^{\circ} \mathrm{C}$.

\section{Conclusions}

This study has developed a new kind of fully bio-based composites from a commercially available resorcinol derivative as a monomer and granular diatomite as fillers. The composite elaboration has followed the green two-stage process which is inspired by the living character of the cationic polymerization. This practical two-stage process, consisting in the photoinitiation and then the thermal dark curing, has allowed to obtain thick and non-transparent epoxy-diatomite composites without any solvent or amine-based hardener. The influence of diatomite content and the compacting pressure on microstructural, thermal, mechanical, and acoustic properties as well as the flame behavior of the obtained composites have been investigated. It is noted that the increase in the diatomite content leads to the increase in the overall composite porosity by the presence of more interparticle and intraparticle voids. Additionally, while good adhesion between the resin and diatomite grains is obtained in case of 30-50 wt.\% diatomite, weak connections among grains are observed for composites with $60 \mathrm{wt} . \%$ diatomite. It is revealed that there exist two failure mechanisms of the studied composites: fractures of diatomite grains when the diatomite content is from 30 to $50 \mathrm{wt} . \%$, and failure of weak connections among filler granules when the diatomite content is as high as $60 \mathrm{wt} . \%$. In addition, the incorporation of diatomite leads to a drop of about $50^{\circ} \mathrm{C}$ in the glass transition temperatures $T_{g}$ of the composites compared to that of the pure resin. Furthermore, when the amount of diatomite increases, $T_{g}$ decreases accordingly. The drop in $T_{g}$ is attributed to two factors. On the one hand, the thermal insulation characteristic of diatomite limits the heat diffusion during polymerization, causing faults in the cross-linked network. On the other hand, a higher diatomite content leads to more dispersion of active molecules in the resin mixture and hence decreases reaction efficiency. It is also shown that the flexural modulus of the composites with 30-50 wt.\% diatomite is enhanced in comparison with that of the pure resin. However, the increase in the overall porosity and the change of the failure mechanism when raising the diatomite content lessen mechanical properties of the composites, especially in case of the $60 \mathrm{wt} . \%$ diatomite composite. In contrast, the increase in the diatomite content helps to improve the composite sound absorption performance, particularly at low frequencies. As regards the flame behavior, the flame retardancy feature of the diatomite-based composites is highlighted by their self-extinguishing behavior and by great reductions of their pHRR and THR compared to those of the pure resin. In addition, the pHRR and THR tend to decrease when the diatomite content increases. The fact that no dripping behavior and no shrinkage were observed for composites during the vertical burning tests and there existed large amounts of composite residues with great cohesion also discloses the flame resistance behavior of the studied composites and their structural integrity when subjected to the flame. Both the flame retardancy and the flame resistance characteristics along with 
the structural integrity are key features for potential applications of the studied diatomitebased composites in the construction industry. Concerning the compacting pressure, its increase reduces the porosity and hence improves mechanical properties. Nevertheless, the decrease of the porosity by raising the compacting pressure diminishes the sound absorption capacity of the composite. It is demonstrated that the variation of the compacting pressure has no much effect on composite flammability. Taking into account a compromise among mechanical, acoustic and flame-retardant properties, the diatomite content of $50 \mathrm{wt} . \%$ and the compacting pressure of $3.9 \mathrm{MPa}$ are considered optimal values in the present work which have resulted in the composite with the flexural modulus of 2.9 MPa, the MSAA of 0.08 (for a sample thickness of $5 \mathrm{~mm}$ ), the pHRR of $109 \mathrm{~W} / \mathrm{g}$ and the THR of $5 \mathrm{~kJ} / \mathrm{g}$. Such composite exhibits the enhanced flexural modulus compared to that of the pure resin, the satisfying sound absorption performance at low frequencies and the impressive flame retardancy behavior compared with other well-known high performance flame-retardant polymers. For deeper insights into microstructures-properties relation, the effects of microstructural features of the studied composites on simultaneously their effective mechanical, acoustic and thermal properties will be the topic of a further study. Within such a study, pore characteristics will be characterized by X-ray microtomography and imaging techniques, and a multiscale approach [58-61] will be applied to perform numerical parametric investigations, towards the optimization of microstructures for the best properties of interest.

Supplementary Materials: The following are available online at https:/ /www.mdpi.com/2673-4 079/2/1/3/s1, Figure S1: FTIR spectrum of diato-mite showing the characteristic bands of silica at $1047 \mathrm{~cm}^{-1}$ (Si-O-Si asymmetric stretching ), $799 \mathrm{~cm}^{-1}$ (Si-O symmetric stretching vibration in amorphous silica), $556 \mathrm{~cm}^{-1}$ (Si-O stretching vibration corresponding to defect $\mathrm{SiO}_{2}$ structural unit) and $451 \mathrm{~cm}^{-1}$ (O-Si-O deformation vibration), Figure S2: DSC thermograms of (a) the pure resin and (b) composites with different diatomite contents. The composites were obtained with $3.5 \mathrm{wt} . \%$ Iod, $2.5 \mathrm{~min}$ irradiation, 3.9 MPa compaction, and $48 \mathrm{~h}$ thermal treatment at $130{ }^{\circ} \mathrm{C}$; Figure S3: HRR curve obtained in the PCFC test for diatomite; Figure S4: HRR curves obtained in PCFC tests for composite samples with different compacting pressures. The composites were obtained with 50 wt. $\%$ diatomite, $3.5 \mathrm{wt} . \%$ Iod, $2.5 \mathrm{~min}$ irradia-tion, and $48 \mathrm{~h}$ thermal treatment at $130^{\circ} \mathrm{C}$. Video S1: Video_1-Pure_resin; Video S2: Video_2-30wt\%diatomite; Video S3: Video_3-40wt\%diatomite; Video S4: Video_4-50wt\%diatomite; Video S5: Video_5-60wt\%diatomite.

Author Contributions: Conceptualization, Q.-B.N., E.R., A.R.d.A.; methodology, Q.-B.N., E.R., A.R.d.A., D.-L.V.; validation, all authors; formal analysis and investigation, Q.-B.N., A.R.d.A., C.P., H.V.; writing—original draft preparation, Q.-B.N.; writing—review and editing, all authors; supervision, E.R., A.R.d.A., S.N., V.-H.N.; funding acquisition, S.N. and E.R. All authors have read and agreed to the published version of the manuscript.

Funding: This research received no external funding.

Institutional Review Board Statement: Not applicable.

Informed Consent Statement: Not applicable.

Acknowledgments: This work has benefited from a French government grant managed by ANR within the frame of the national program of Investments for the Future ANR-11-LABX-022- 01 (LabEx MMCD project). The authors are indebted to Léon Preira (ICMPE) for the fabrication of two specific molds used in the study. H. Vahabi also would like to thank IUT de Moselle Est-"Plastinnov" for the PCFC tests.

Conflicts of Interest: The authors declare no conflict of interest. 


\section{References}

1. Van Garderen, N.; Clemens, F.J.; Mezzomo, M.; Bergmann, C.P.; Graule, T. Investigation of Clay Content and Sintering Temperature on Attrition Resistance of Highly Porous Diatomite Based Material. Appl. Clay Sci. 2011, 52, 115-121. [CrossRef]

2. Parkinson, J.; Gordon, R. Beyond Micromachining: The Potential of Diatoms. Trends Biotechnol. 1999, 17, 190-196. [CrossRef]

3. Akin, S.; Schembre, J.M.; Bhat, S.K.; Kovscek, A.R. Spontaneous Imbibition Characteristics of Diatomite. J. Pet. Sci. Eng. 2000, 25, 149-165. [CrossRef]

4. Lee, S.; Ha, J.-H.; Lee, J.; Song, I.-H.; Kwon, S.-H. Preparation and Characterization of a Low-Cost and Natural Material-Based Reticulated Porous Diatomite-Kaolin Composite. Appl. Sci. 2020, 10, 2125. [CrossRef]

5. Mateo, S.; Cuevas, M.; La Rubia, M.D.; Eliche-Quesada, D. Preliminary Study of the Use of Spent Diatomaceous Earth from the Brewing Industry in Clay Matrix Bricks. Adv. Appl. Ceram. 2017, 116, 77-84. [CrossRef]

6. Pimraksa, K.; Chindaprasirt, P. Lightweight Bricks Made of Diatomaceous Earth, Lime and Gypsum. Ceram. Int. 2009, 35, 471-478. [CrossRef]

7. Escalera, E.; Garcia, G.; Terán, R.; Tegman, R.; Antti, M.-L.; Odén, M. The Production of Porous Brick Material from Diatomaceous Earth and Brazil Nut Shell Ash. Constr. Build. Mater. 2015, 98, 257-264. [CrossRef]

8. Zheng, S.; Bai, C.; Gao, R. Preparation and Photocatalytic Property of TiO2 /Diatomite-Based Porous Ceramics Composite Materials. Int. J. Photoenergy 2012, 2012, 1-4. [CrossRef]

9. Zeren, D.; Güden, M. The Increased Compression Strength of an Epoxy Resin with the Addition of Heat-Treated Natural Nano-Structured Diatom Frustules. J. Compos. Mater. 2017, 51, 1681-1691. [CrossRef]

10. Leskovac, M.; Kovačević, V.; Lučić, S.; Perrott, H.R.; Šmit, I. Composites of Poly(Acrylate) Copolymer Filled with Diatomaceous Earth: Morphology and Mechanical Behaviour. Mater. Res. Innov. 2002, 6, 206-213. [CrossRef]

11. Cacciotti, I.; Rinaldi, M.; Fabbrizi, J.; Nanni, F. Innovative Polyetherimide and Diatomite Based Composites: Influence of the Diatomite Kind and Treatment. J. Mater. Res. Technol. 2019, 8, 1737-1745. [CrossRef]

12. Wang, J.; Zhao, D.; Liu, Z.; Chen, H.; Zhou, Y.; Zhou, Y.; Zhu, B. Effects of Biomass Diatom Frustule on Structure and Properties of Polyurethane Elastomer. J. Appl. Polym. Sci. 2020, 137, 48452. [CrossRef]

13. Dobrosielska, M.; Przekop, R.; Sztorch, B.; Brząkalski, D.; Zgłobicka, I.; Łępicka, M.; Dobosz, R.; Kurzydłowski, K. Biogenic Composite Filaments Based on Polylactide and Diatomaceous Earth for 3D Printing. Materials 2020, 13, 4632. [CrossRef]

14. Fu, Y.; Xu, X.; Huang, Y.; Hu, J.; Chen, Q.; Wu, Y. Preparation of New Diatomite-Chitosan Composite Materials and Their Adsorption Properties and Mechanism of Hg(II). R. Soc. Open Sci. 2017, 4, 170829. [CrossRef] [PubMed]

15. Wu, W.; Cong, S. Modified Diatomite Forms in the Rubber Nanocomposites. J. Thermoplast. Compos. Mater. 2020, 33, 659-672. [CrossRef]

16. Benayache, S.; Alleg, S.; Mebrek, A.; Suñol, J.J. Thermal and Microstructural Properties of Paraffin/Diatomite Composite. Vacuum 2018, 157, 136-144. [CrossRef]

17. Xu, G.; Leng, G.; Yang, C.; Qin, Y.; Wu, Y.; Chen, H.; Cong, L.; Ding, Y. Sodium Nitrate - Diatomite Composite Materials for Thermal Energy Storage. Sol. Energy 2017, 146, 494-502. [CrossRef]

18. Wang, R.-M.; Zheng, S.-R.; Zheng, Y.-P. Polymer Matrix Composites and Technology; Woodhead Publishing Limited: Cambridge, UK, 2011; ISBN 978-0-85709-221-2.

19. Jin, F.-L.; Li, X.; Park, S.-J. Synthesis and Application of Epoxy Resins: A Review. J. Ind. Eng. Chem. 2015, 29, 1-11. [CrossRef]

20. Liu, Y.-L.; Hsu, C.-Y.; Wei, W.-L.; Jeng, R.-J. Preparation and Thermal Properties of Epoxy-Silica Nanocomposites from Nanoscale Colloidal Silica. Polymer 2003, 44, 5159-5167. [CrossRef]

21. Kosbar, L.L.; Gelorme, J.D.; Japp, R.M.; Fotorny, W.T. Introducing Biobased Materials into the Electronics Industry. J. Ind. Ecol. 2000, 4, 93-105. [CrossRef]

22. Pan, H. Synthesis of Polymers from Organic Solvent Liquefied Biomass: A Review. Renew. Sustain. Energy Rev. 2011, 15, 3454-3463. [CrossRef]

23. Nikafshar, S.; Zabihi, O.; Hamidi, S.; Moradi, Y.; Barzegar, S.; Ahmadi, M.; Naebe, M. A Renewable Bio-Based Epoxy Resin with Improved Mechanical Performance That Can Compete with DGEBA. RSC Adv. 2017, 7, 8694-8701. [CrossRef]

24. Nguyen, Q.; Nguyen, N.; Rios de Anda, A.; Nguyen, V.; Versace, D.; Langlois, V.; Naili, S.; Renard, E. Photocurable Bulk Epoxy Resins Based on Resorcinol Derivative through Cationic Polymerization. J. Appl. Polym. Sci. 2020, 137, 10. [CrossRef]

25. Bourne, L.B.; Milner, F.J.M.; Alberman, K.B. Health Problems of Epoxy Resins and Amine-Curing Agents. Occup. Environ. Med. 1959, 16, 81-97. [CrossRef] [PubMed]

26. Hua, Y.; Xiao-Xue, W.; Qian-ying, W.; Ying, Z. Sound Absorption Performance of Diatom Mud Coating and Its Influence on Indoor Acoustic Environment. Ferroelectrics 2019, 549, 241-253. [CrossRef]

27. Jin, H.-Y.; Yang, Y.-Q.; Xu, L.; Hou, S.-E. Effects of Spherical Silica on the Properties of an Epoxy Resin System. J. Appl. Polym. Sci. 2011, 121, 648-653. [CrossRef]

28. Yang, P.; Ren, M.; Chen, K.; Liang, Y.; Lü, Q.-F.; Zhang, T. Synthesis of a Novel Silicon-Containing Epoxy Resin and Its Effect on Flame Retardancy, Thermal, and Mechanical Properties of Thermosetting Resins. Mater. Today Commun. 2019, 19, 186-195. [CrossRef]

29. Liu, Y.-L.; Wu, C.-S.; Chiu, Y.-S.; Ho, W.-H. Preparation, Thermal Properties, and Flame Retardance of Epoxy-Silica Hybrid Resins. J. Polym. Sci. Part A Polym. Chem. 2003, 41, 2354-2367. [CrossRef]

30. Gu, H.; Guo, J.; He, Q.; Tadakamalla, S.; Zhang, X.; Yan, X.; Huang, Y.; Colorado, H.A.; Wei, S.; Guo, Z. Flame-Retardant Epoxy Resin Nanocomposites Reinforced with Polyaniline-Stabilized Silica Nanoparticles. Ind. Eng. Chem. Res. 2013, 52, 7718-7728. [CrossRef]

31. Zhang, C.; Wang, J.; Song, S. Preparation of a Novel Type of Flame Retardant Diatomite and Its Application in Silicone Rubber Composites. Adv. Powder Technol. 2019, 30, 1567-1575. [CrossRef] 
32. Bulut, U.; Crivello, J.V. Investigation of the Reactivity of Epoxide Monomers in Photoinitiated Cationic Polymerization. Macromolecules 2005, 38, 3584-3595. [CrossRef]

33. Goethals, E.; Duprez, F. Carbocationic Polymerizations. Prog. Polym. Sci. 2007, 32, 220-246. [CrossRef]

34. Washburn, E.W. The Dynamics of Capillary Flow. Phys. Rev. 1921, 17, 273-283. [CrossRef]

35. Lowell, S.; Shields, J.E.; Thomas, M.A.; Thommes, M. Characterization of Porous Solids and Powders: Surface Area, Pore Size and Density; Particle Technology Series; Springer: Dordrecht, The Netherlands, 2004; Volume 16, ISBN 978-90-481-6633-6.

36. De Anda, A.R.; Fillot, L.A.; Rossi, S.; Long, D.; Sotta, P. Influence of the Sorption of Polar and Non-Polar Solvents on the Glass Transition Temperature of Polyamide 6,6 Amorphous Phase. Polym. Eng. Sci. 2011, 51, 2129-2135. [CrossRef]

37. Rios De Anda, A.; Fillot, L.A.; Preda, F.M.; Rossi, S.; Long, D.R.; Sotta, P. Sorption and Plasticization Effects of Ethanol-TolueneIsooctane Ternary Mixtures in Polyamide 6,6 and Induced Plasticization Effects. Eur. Polym. J. 2014, 55, 199-209. [CrossRef]

38. Rios de Anda, A.; Fillot, L.-A.; Long, D.R.; Sotta, P. Influence of the Amorphous Phase Molecular Mobility on Impact and Tensile Properties of Polyamide 6,6. J. Appl. Polym. Sci. 2016, 133, 9. [CrossRef]

39. ASTM D790-03: Standard Test Methods for Flexural Properties of Unreinforced and Reinforced Plastics and Electrical Insulating Materials; ASTM International: West Conshohocken, PA, USA, 2003.

40. ISO 10534-2: Acoustics-Determination of Sound Absorption Coefficient and Impedance in Impedance Tubes. Part 2: Transfer-Function Method; International Organization for Standardization: Geneva, Switzerland, 1998.

41. Salissou, Y.; Panneton, R. Wideband Characterization of the Complex Wave Number and Characteristic Impedance of Sound Absorbers. J. Acoust. Soc. Am. 2010, 128, 2868-2876. [CrossRef]

42. ASTM C423: Standard Test Method for Sound Absorption and Sound Absorption Coefficients by the Reverberation Room Method; ASTM International: West Conshohocken, PA, USA, 2002.

43. Huggett, C. Estimation of Rate of Heat Release by Means of Oxygen Consumption Measurements. Fire Mater. 1980, 4, 61-65. [CrossRef]

44. Chaisena, A.; Rangsriwatananon, K. Effects of Thermal and Acid Treatments on Some Physico-Chemical Properties of Lampang Diatomite. Suranaree J. Sci. Technol. 2004, 11, 289-299.

45. Kulpe, J.A.; Lee, C.-Y.; Leamy, M.J. Computation of Acoustic Absorption in Media Composed of Packed Microtubes Exhibiting Surface Irregularity. J. Acoust. Soc. Am. 2011, 130, 826-834. [CrossRef]

46. Swift, M.J.; Bris, P.; Horoshenkov, K.V. Acoustic Absorption in Re-Cycled Rubber Granulate. Appl. Acoust. 1999, 57, $203-212$. [CrossRef]

47. Bifulco, A.; Parida, D.; Salmeia, K.A.; Nazir, R.; Lehner, S.; Stämpfli, R.; Markus, H.; Malucelli, G.; Branda, F.; Gaan, S. Fire and Mechanical Properties of DGEBA-Based Epoxy Resin Cured with a Cycloaliphatic Hardener: Combined Action of Silica, Melamine and DOPO-Derivative. Mater. Des. 2020, 193, 108862. [CrossRef]

48. Butler, S.; Fotsing, E.R.; Ross, A. Acoustic Thermoset Open-Cell Foams Produced by Particulate Leaching Process. J. Mater. Sci. 2019, 54, 12553-12572. [CrossRef]

49. Ali, M.S.; Mohamed Ariff, A.H.; Jaafar, C.N.A.; Tahir, S.M.; Mazlan, N.; Maori, K.A.; Naser, H. Factors Affecting the Porosity and Mechanical Properties of Porous Ceramic Composite Materials. In Reference Module in Materials Science and Materials Engineering; Elsevier: Amsterdam, The Netherlands, 2017; ISBN 978-0-12-803581-8.

50. Patel, P.S.; Shepherd, D.E.; Hukins, D.W. Compressive Properties of Commercially Available Polyurethane Foams as Mechanical Models for Osteoporotic Human Cancellous Bone. BMC Musculoskelet. Disord. 2008, 9. [CrossRef] [PubMed]

51. Yang, S.-Y. Advanced Polyimide Materials: Synthesis, Characterization, and Applications; Elsevier: Amsterdam, The Netherlands, 2018; ISBN 978-0-12-812641-7.

52. Sonnier, R.; Vahabi, H.; Ferry, L.; Lopez-Cuesta, J.-M. Pyrolysis-Combustion Flow Calorimetry: A Powerful Tool To Evaluate the Flame Retardancy of Polymers. In Fire and Polymers VI: New Advances in Flame Retardant Chemistry and Science; Morgan, A.B., Wilkie, C.A., Nelson, G.L., Eds.; ACS Symposium Series; American Chemical Society: Washington, DC, USA, 2012; Volume 1118, pp. 361-390. ISBN 978-0-8412-2780-4.

53. ASTM D7309-20: Standard Test Method for Determining Flammability Characteristics of Plastics and Other Solid Materials Using Microscale Combustion Calorimetry; ASTM International: West Conshohocken, PA, USA, 2020.

54. Lyon, R.E.; Walters, R.N. A Microscale Combustion Calorimeter; Federal Aviation Administration, Office of Aviation Research: Washington, DC, USA, 2002.

55. Wu, H.; Sulkis, M.; Driver, J.; Saade-Castillo, A.; Thompson, A.; Koo, J.H. Multi-Functional ULTEM ${ }^{\text {TM }} 1010$ Composite Filaments for Additive Manufacturing Using Fused Filament Fabrication (FFF). Addit. Manuf. 2018, 24, 298-306. [CrossRef]

56. Butnaru, I.; Bruma, M.; Gaan, S. Phosphine Oxide Based Polyimides: Structure-Property Relationships. RSC Adv. 2017, 7 , 50508-50518. [CrossRef]

57. Schartel, B.; Wilkie, C.A.; Camino, G. Recommendations on the Scientific Approach to Polymer Flame Retardancy: Part 1Scientific Terms and Methods. J. Fire Sci. 2016, 34, 447-467. [CrossRef]

58. Nguyen, Q.-B.; Nguyen, V.-H.; Perrot, C.; Rios de Anda, A.; Renard, E.; Naili, S. Multiscale Approach to Characterize Effective Mechanical, Hydraulic and Acoustic Properties of a New Bio-Based Porous Material. Mater. Today Commun. 2021, $26,101938$. [CrossRef] 
59. Yorov, K.E.; Kottsov, S.Y.; Baranchikov, A.E.; Boytsova, O.V.; Kiskin, M.A.; Varaksina, E.A.; Kopitsa, G.P.; Lermontov, S.A.; Sidorov, A.A.; Pipich, V.; et al. Photoluminescent Porous Aerogel Monoliths Containing ZnEu-Complex: The First Example of Aerogel Modified with a Heteronuclear Metal Complex. J. Sol Gel Sci. Technol. 2019. [CrossRef]

60. Brinker, C.J.; Scherer, G.W. Sol-Gel Science-The Physics and Chemistry of Sol-Gel Processing; Academic Press Inc.: Cambridge, MA, USA, 1990.

61. Al-Oweini, R.; El-Rassy, H. Synthesis and Characterization by FTIR Spectroscopy of Silica Aerogels Prepared Using Several $\mathrm{Si}(\mathrm{OR}) 4$ and $\mathrm{R}^{\prime \prime} \mathrm{Si}\left(\mathrm{OR}^{\prime}\right) 3$ Precursors. J. Mol. Struct. 2009, 919, 140-145. [CrossRef] 